\title{
Bayesian Estimation of Source Parameters and Associated Coulomb Failure Stress Changes for the 2005 Fukuoka
}

\section{(Japan) Earthquake}

Rishabh Dutta, Sigurjón Jónsson, Teng Wang* and Hannes Vasyura-Bathke Division of Physical Sciences and Engineering,

King Abdullah University of Science and Technology (KAUST),

Thuwal 23955-6900, Saudi Arabia.

* Now at Earth Observatory of Singapore (EOS),

Nanyang Technological University, Singapore.

E-mail: rishabh.dutta@kaust.edu.sa 
Dutta, R., Jónsson, S., Wang, T. \& Vasyura-Bathke, $H$.

\section{SUMMARY}

Several researchers have studied the source parameters of the 2005 Fukuoka (northwestern Kyushu Island, Japan) earthquake ( $M_{W}$ 6.6) using teleseismic, strong motion and geodetic data. However, in all previous studies, errors of the estimated fault solutions have been neglected, making it impossible to assess the reliability of the reported solutions. We use Bayesian inference to estimate the location, geometry and slip parameters of the fault and their uncertainties using Interferometric Synthetic Aperture Radar (InSAR) and Global Positioning System (GPS) data. The offshore location of the earthquake makes the fault parameter estimation challenging, with geodetic data coverage mostly to the southeast of the earthquake. To constrain the fault parameters, we use a priori constraints on the magnitude of the earthquake and the location of the fault with respect to the aftershock distribution and find that the estimated fault slip ranges from $1.5 \mathrm{~m}$ to 2.5 $\mathrm{m}$ with decreasing probability. The marginal distributions of the source parameters show that the location of the western end of the fault is poorly constrained by the data whereas that of the eastern end, located closer to the shore, is better resolved. We propagate the uncertainties of the fault model and calculate the variability of Coulomb failure stress changes for the nearby Kego fault, located directly below Fukuoka city, showing that the mainshock increased stress on the fault and brought it closer to failure.

Key words: Earthquake source estimations, Fukuoka earthquake, Bayesian inference, Coulomb failure stress changes, GPS, InSAR. 


\section{INTRODUCTION}

Earthquakes occur when shear stresses on a fault overcome clamping of normal stresses and friction. The Coulomb failure criterion (Harris 1998; King et al. 1994; Stein et al. 1992) is used to characterize the stress conditions at which failure can occur. An earthquake modifies the stresses in the surrounding rocks and may thus either delay the next earthquake on a nearby fault or hasten it according to this failure criterion. A nearby mapped fault is considered moved closer to failure if changes in Coulomb failure stress ( $\triangle \mathrm{CFS}$ ) due to an earthquake are positive and is further from failure if $\Delta \mathrm{CFS}$ is negative (e.g., Deng \& Sykes 1997; Hincapie et al. 2005; Hodgkinson et al. 1996; Lin \& Stein 2004; Nalbant et al. 1998; Parsons et al. 2000, 2008; Stein et al. 1994, 1997).

Many past studies focused on stress interactions between earthquakes. Deng \& Sykes (1997) found that $95 \%$ of magnitude 6.0 and greater earthquakes with strike-slip and dip-slip mechanisms in southern California occurred in areas of increased $\triangle$ CFS. Stein et al. (1997) inferred that nine out of ten large earthquakes along the North Anatolian Fault between 1939 and 1992 occurred where $\triangle$ CFS was increased by the previous earthquake. Parsons et al. (2000) showed that the 1999 Izmit earthquake $\left(M_{W} 7.6\right)$ occurred in an area of increased stress, which in turn increased $\Delta$ CFS on a fault in Düzce that ruptured three months later. Nalbant et al. (1998) studied the stress interaction between faults in the back-arc extensional region of the northern Aegean Sea and between segments of the North Anatolian Fault in the Sea of Marmara where there had been large earthquakes in the past. They found that 23 of the 29 events (strike-slip, normal and oblique fault mechanisms) occurred in areas of increased Coulomb stress due to preceding earthquakes. Similarly, Doser \& Robinson (2002) found that six of the seven events with magnitude between 5.9 and 7 in southern Marlborough region, east of the Alpine fault in New Zealand, occurred where the $\triangle \mathrm{CFS}$ was increased by the preceding earthquake by $10 \mathrm{kPa}$ or more.

Most studies of changes in the Coulomb failure stress have ignored uncertainties in the calculated $\triangle \mathrm{CFS}$ although such uncertainties can be quite significant and can vary at different locations around the source fault (Woessner et al. 2012). These uncertainties can be calculated by propagating uncertainties in the fault model (Hainzl et al. 2009; Lohman \& Barnhart 2010; Woessner et al. 2012) and by including uncertainties in the geometry of the receiver fault (Steacy et al. 2005). Estimating a fault model with unknown geometry from geodetic data is a nonlinear problem, in which uncertainties of estimated parameters arise from uncertainties in the data and the earth model.

Uncertainties in fault model parameters have been quantified in the past by obtaining an ensemble of fault models describing the data (e.g., Cervelli et al. 2001; Duputel et al. 2014; Funning et al. 2005; Monelli et al. 2009; Sudhaus \& Jónsson 2009; Sudhaus \& Jónsson 2011; Fukuda \& Johnson 2008; Sun et al. 2011; Xu et al. 2015). Some authors have used Bayesian estimation of the fault-slip 
model parameters to obtain their posterior distributions (e.g., Duputel et al. 2014; Monelli et al. 2009; Fukuda \& Johnson 2008; Sun et al. 2011; Xu et al. 2015). However, they used only geodetic and/or seismic data to constrain the fault parameters, even though the Bayesian method also allows auxiliary physical information about the fault to be used when constraining the fault-slip model. Although some regularization constraints (like slip smoothness) have previously been used as a priori information about fault-slip patches (Fukuda \& Johnson 2008), physical constraints on the fault geometry (such as strike and dip), e.g., from locations and focal mechanisms of aftershocks, or from the moment magnitude of the earthquake, have seldom been used in Bayesian estimation. Such physical constraints can be useful with limited data that poorly constrain the fault model (e.g., Xu et al. 2015). In this paper, we show how locations of aftershocks and the magnitude of the mainshock can be used as a priori information in Bayesian fault model estimation.

We use the $2005 M_{W} 6.6$ Fukuoka earthquake as a case study. This earthquake occurred about 20 km offshore and northwest of Fukuoka city (northern Kyushu Island, Japan), which had a population of 1.4 million in 2005 (Fig. 1). It ruptured a previously unknown fault with a left-lateral strike-slip. This fault is now considered to be an extension of the Kego fault (Shimizu et al. 2007), which was mapped by Karakida et al. (1994), has a similar NW-SE trend, and lies directly under Fukuoka city. A possible future earthquake of similar magnitude on the Kego fault would be devastating to the city and might threaten critical facilities, such as the Genkai nuclear power plant, which is only about 50 $\mathrm{km}$ away from the Kego fault.

The Fukuoka earthquake was studied shortly after it took place by several researchers, e.g., by using teleseismic, strong motion and geodetic data (Asano \& Iwata 2006; Horikawa 2006; Kobayashi et al. 2006; Nishimura et al. 2006; Ozawa et al. 2006; Sekiguchi et al. 2006; Suzuki \& Iwata 2006; Takenaka et al. 2006). However, none of these authors reported uncertainties in their fault solutions, making it difficult to assess differences between solutions and the reliability of calculated $\triangle \mathrm{CFS}$ on and near the Kego fault. In this study, we use both GPS and InSAR data to constrain the offshore fault location and geometry. We also develop an approach to include the magnitude of the mainshock and the locations of the aftershocks as a priori information in constraining the model parameters. To understand the stress interaction between the fault that ruptured and the Kego fault, we calculate the $\triangle \mathrm{CFS}$ along the Kego fault and assess the reliability of $\triangle \mathrm{CFS}$ by propagating the fault model uncertainties in the calculation.

\section{STUDY AREA}

The $M_{W} 6.6$ Fukuoka earthquake occurred at 10:53 a.m. on 20 March 2005 (JST) beneath the Genkai Sea, northwest of Shika Island (or Shikanoshima in Fig. 2), which is located just off the northwestern 
coast of Kyushu Island in Japan. One death was confirmed and around 1000 people were injured in the earthquake. It also caused severe damage to buildings on Genkai Island (Fig. 2) and the total economic loss was estimated to be about 150 million US dollars. The tectonics in northern Kyushu is less active than in most other parts of Japan, the last large earthquake in the region being the $1700 M_{W} 7$ Tsushima earthquake (Matsumoto et al. 2006). The last destructive earthquake in northern Kyushu was the $1898 M_{J M A} 6$ Itoshima earthquake (Shimizu et al. 2007). The tectonics around the northern coast of Kyushu is characterized by N-S extension with a crustal strain rate of approximately $5 \mathrm{e}-8$ $y r^{-1}$ during the past 100 years (Shimizu et al. 2007). Most seismicity in Kyushu is related to the subduction of the Philippine Sea plate at depth. A $M_{W} 7.1$ earthquake ruptured beneath Kumamoto city in central Kyushu in April 2016, causing 35 deaths and around 2000 injuries. This earthquake followed magnitude $M_{W} 6.2$ and 6.0 foreshocks that occurred in the same region and caused nine fatalities. Central Kyushu also experienced two earthquakes of magnitudes 5.8 and 6.1 in January and April of 1975, respectively. These earlier earthquakes occurred 40-60 km northwest of the later 2016 event and caused injuries, but no known fatalities.

The Fukuoka earthquake occurred on a previously undocumented NW-SE fault with a predominantly left-lateral strike slip. Uehira et al. (2006) deployed 11 ocean-bottom seismometers and 24 temporary onland stations around the aftershock area to locate the aftershock activity and provide information on the location of the source fault of the mainshock (Fig. 1). These aftershock locations suggest that an approximately $25 \mathrm{~km}$ long NW-SE striking fault ruptured during the mainshock, which was nearly vertical at depths of 2-16 km (Shimizu et al. 2007). No surface ruptures on the sea-floor were found during a sonic prospecting survey carried out by the Japan Coast Guard after the earthquake (Sekiguchi et al. 2006; Takenaka et al. 2006). From focal mechanisms of 1333 aftershocks and using a damped regional-scale stress inversion technique (Hardebeck \& Michael 2006), the maximum principal compressive stress $\left(\sigma_{1}\right)$ and the minimum principal stress $\left(\sigma_{3}\right)$ were estimated to be directed WSW-ENE and NNW-SSE, respectively (Matsumoto et al. 2012).

As noted, several studies focused on estimating the fault parameters of the earthquake using teleseismic, strong motion and geodetic data (Table 1). Nishimura et al. (2006) used GPS and InSAR data to estimate the fault-slip distribution, however only one InSAR interferogram (from descending track 17 of ENVISAT) was used in their analysis. This interferogram has limited data in both the near-field and the far-field due to the offshore location of the earthquake and decorrelation. Their slip model has a seismic moment of $8.7 \times 10^{18} \mathrm{Nm}$, strike of $\mathrm{N} 118^{\circ} \mathrm{E}$, dip of $79^{\circ}$ (dipping to the northeast) and rake of $18^{\circ}$. Ozawa et al. (2006) also used GPS and InSAR data to estimate the slip distribution on a fault with a fault dip of $90^{\circ}$ and a strike of $122^{\circ}$. They found maximum left-lateral strike slip of $2.4 \mathrm{~m}$, with 
the slip exceeding $1 \mathrm{~m}$ and shallower than $10 \mathrm{~km}$ at the center of the fault and shallower than $4 \mathrm{~km}$ close to the coast.

Asano \& Iwata (2006) performed a kinematic waveform inversion using strong motion data to study the fault rupture process. They observed that the rupture mainly propagated to the southeast from the hypocenter. They observed two slip asperities with the smaller slip asperity shallower and the larger slip asperity deeper than the hypocenter. They estimated the seismic moment to be $1.15 \times 10^{19}$ $\mathrm{Nm}$. Horikawa (2006) also used strong motion data to study the rupture process and also found two slip asperities with the shallower asperity smaller than the deeper asperity. However, they found that the rupture propagated bilaterally with a lower seismic moment $\left(5.7 \times 10^{18} \mathrm{Nm}\right)$. Kobayashi et al. (2006) used both strong motion and 1-Hz GPS data and estimated the seismic moment to be $1 \times 10^{19}$ $\mathrm{Nm}$, with the rupture propagating SE from the hypocenter with only one asperity shallower than the hypocenter.

In yet another study using strong motion data, Sekiguchi et al. (2006) estimated the seismic moment release to be $1.16 \times 10^{19} \mathrm{Nm}$ and the rupture velocity to be $2.1 \mathrm{~km} / \mathrm{s}$. Their estimated slip distribution shows a single asperity that is about $6 \mathrm{~km} \times 8 \mathrm{~km}$ in size. Their solution indicates that the rupture propagated mainly to the southeast and that it started with a high slip-rate at the hypocenter, continuing at a low slip-rate for a few seconds, and then returning to a high slip-rate in the southeast and shallower than the hypocenter. Takenaka et al. (2006) used strong motion data to estimate the geometry of the fault-plane and they found a fault strike of $\mathrm{N} 124^{\circ} \mathrm{E}$ and a fault dip angle of $87^{\circ}$ (dipping to the NE). They then estimated that the fault ruptured in two asperities with the main rupture onset location $5 \mathrm{~km}$ southeast from the hypocenter. They estimated a slow rupture velocity of $1.4 \mathrm{~km} / \mathrm{s}$, which is $40 \%$ of the shear wave velocity.

Most of these kinematic rupture models were estimated using a fault geometry obtained from poorly constrained aftershocks and focal mechanisms that were reported without any uncertainties. In addition, none of the earlier studies reported uncertainties in their fault model solutions. Uncertainties in the source fault solutions directly influence the reliability of $\triangle \mathrm{CFS}$ calculations (Lohman \& Barnhart 2010; Woessner et al. 2012). Here, we consider the influence of the source model errors on $\Delta \mathrm{CFS}$ calculations around the Fukuoka earthquake and in particular along the Kego fault.

\section{DATA}

We used both GPS and InSAR data to estimate the fault geometry and average slip of the Fukuoka earthquake (Fig. 2). The radar data were acquired from two parallel descending tracks by the ENVISAT satellite (tracks 17 and 246). We used the Gamma processing software (Werner et al. 2000) to process the raw SAR data, process the interferograms, and remove the topography-related phase us- 
ing the Shuttle Radar Topography Mission (Farr et al. 2007) 3-arcsec digital elevation model (DEM). We generated a single good-quality interferogram with small temporal and spatial baseline from descending track 246. The signal-to-noise ratio of the interferogram was enhanced by multi-looking and adaptive spectral filtering (Goldstein \& Werner 1998). We then unwrapped the interferogram using a minimum cost-flow algorithm (Chen \& Zebker 2002) and removed a phase ramp by considering the phase in the far-field to be close to zero. It was not possible to generate good-quality interferograms from descending track 17 due to temporal and baseline decorrelation (Zebker \& Villasenor 1992) and atmospheric noise. Instead, we used all the available SAR scenes from this track (Fig. S1), from both before and after the earthquake (21 SAR scenes), to detect stable point targets based on phase coherence. For each point target, we generated displacement time-series from the unwrapped interferograms (formed from the 21 SAR scenes, see Fig. S1) and fitted a step function to estimate the coseismic displacement. Before the modeling, we subsampled all the InSAR data using the quadtree algorithm (Jónsson et al. 2002).

InSAR data from track 246 contain data from only the east side of the fault and mostly from the mainland (Fig. 2b), while data from Shika, Genkai and Nokono Islands, which are within $10 \mathrm{~km}$ of the fault are lost due to decorrelation. This dataset shows a maximum line-of-sight (LOS) uplift of $\sim 6$ $\mathrm{cm}$ and maximum LOS subsidence of $\sim 5 \mathrm{~cm}$ (Fig. 2b). The stable point-target data from track 17 have better coverage, extending to Iki Island, located to the west of the earthquake, and also to Shika, Genkai and Nokono Islands. This dataset shows maximum LOS uplift of $\sim 8 \mathrm{~cm}$ and maximum LOS subsidence of $\sim 4 \mathrm{~cm}$ (Fig. 2a).

We also used GPS data measured at 56 continuous GPS stations and 26 campaign GPS survey sites (Fig. 1). All but four of the continuous GPS stations are from GEONET (GNSS Earth Observation Network System) maintained by GSI (Geospatial Information Authority of Japan). The remaining continuous GPS stations are maintained by GSI for public surveying and one by the Hydrographic and Oceanographic Department of the Japan Coast Guard. The coseismic displacements were derived from the difference in the averages of daily solutions between 10-19 and 21-30 March 2005. Maximum horizontal displacement of $20 \mathrm{~cm}$ and vertical displacement of $4 \mathrm{~cm}$ were observed at the Shika Island station (Fig. 2c).

The campaign GPS measurements at the 26 sites were carried out by GSI on 27-31 March 2005. The preseismic measurements were mostly from 1994. The maximum coseismic horizontal displacement of $38 \mathrm{~cm}$ was observed on Genkai Island (Fig. 2c). These measurements include contributions from interseimic displacements between 1994 and 2005 as well as errors related to the centering of the GPS antennae. The accuracy of the vertical campaign GPS displacements is low compared to that of the horizontal displacements. In general, the uncertainties of the campaign GPS measurements are 
much larger than those of the continuous GPS measurements (Nishimura et al. 2006). The uncertainties are accommodated accordingly in the data covariance matrix used in the estimation.

\section{METHODOLOGY}

We used Bayesian estimation to determine the fault model parameters of the Fukuoka earthquake. In the Bayesian approach, we estimate the multi-dimensional posterior PDF defined on the model space using an iterative stochastic Markov Chain Monte Carlo (MCMC) method. This posterior PDF incorporates specified prior information about the model space, and the physical law relating the model parameters with the data (linearly or non-linearly). The model parameter uncertainties are then analyzed from the one-dimensional (1D) and two-dimensional (2D) posterior marginal probability distribution functions. Here, we begin by describing the parameterization of the fault-slip model and then we present the formulations of the prior PDF, the likelihood function and the posterior PDF.

\subsection{Fault model parameterization}

The model parameter vector, $\mathbf{m}$ in the $M$-dimensional model space $\mathbb{M}$, in our problem relates nonlinearly to the data vector, $\mathbf{d}$ in the $N$-dimensional data space $\mathbb{D}: \mathbf{d}=G(\mathbf{m})+\epsilon_{\mathbf{1}}$, where $G(\mathbf{m})$ are the predicted data with $\epsilon_{\mathbf{1}}$ errors. Here, the unit of $\mathbf{d}, G(\mathbf{m})$ and $\epsilon_{\mathbf{1}}$ is meters. We used a rectangular planar fault with a uniform left-lateral strike-slip placed within a homogeneous and isotropic elastic halfspace to represent our fault model (Okada 1985), which can be parameterized by eight parameters. The seven geometrical parameters are the easting and westing coordinates of the two endpoints of the fault (top edge), the fault depth (from the top edge), width and dip. The eighth parameter is the amount of left-lateral strike-slip on the fault surface. We chose to estimate the end-point locations of the fault, instead of using one center coordinate along with the fault's length and strike, as the data can constrain the near-shore east end of the fault much better than its west end, which is located further offshore (Fig. 1). The dip-slip parameter was set to zero for simplicity and because the Fukuoka earthquake was predominantly a left-lateral strike-slip event.

\subsection{Bayesian inference}

Using the Bayesian approach, we estimate the posterior probability distribution function (PDF) of the model parameters, $\mathbf{m}$, given the data, $\mathbf{d}$, and their uncertainties. It allows us to use two states of information, a priori information of the model parameters and data, to obtain an estimate of the posterior PDF of the model parameters (Tarantola 2005):

$$
\sigma_{M}(\mathbf{m})=k \rho_{M}(\mathbf{m}) \mathbb{L}(\mathbf{m})
$$


where $k$ is a normalizing constant, $\rho_{M}(\mathbf{m})$ is the probability density representing a priori information of the model parameters and $\mathbb{L}(\mathbf{m})$ is the likelihood function.

\subsubsection{Likelihood function}

The Likelihood function $(\mathbb{L}(\mathbf{m})$ in Eq. 1) is a measure of how probable are the model parameters $\mathbf{m}$ in explaining the data and can be given as (Monelli et al. 2009; Tarantola 2005):

$$
\mathbb{L}(\mathbf{m})=\int_{\mathbb{D}} \rho_{D}(\mathbf{d}) \theta(\mathbf{d} \mid \mathbf{m}) d \mathbf{d} .
$$

The conditional probability density $\theta(\mathbf{d} \mid \mathbf{m})$ represents the correlation between model parameters and data, which accommodates the model uncertainties. Usually, the model uncertainties arise due to the heterogeneity in Earth's structure, inelasticity and the modeling scheme (Fukuda \& Johnson 2008; Yagi \& Fukahata 2008, 2011). Considering negligible model uncertainties in our study due to limited effects of crustal structure complexities on predicted GPS/InSAR displacements (Monelli et al. 2009), we take $\theta(\mathbf{d} \mid \mathbf{m})=\delta(\mathbf{d}-G(\mathbf{m}))$, where $G(\mathbf{m})$ is the forward modeling operator. The prior PDF on the data is represented by $\rho_{D}(\mathbf{d})$, where we consider our observed values $\mathbf{d}_{o b s}$ to have Gaussian uncertainties described by a data covariance matrix $\Sigma_{d}$. Here, the unit of $\mathbf{d}_{o b s}$ is $m$ (meters), and unit of $\Sigma_{d}$ is $m^{2}$. The Gaussian probability density $\rho_{D}(\mathbf{d})$ centered at $\mathbf{d}_{o b s}$ is thus given as:

$$
\rho_{D}(\mathbf{d})=\frac{1}{(2 \pi)^{N / 2}\left|\Sigma_{d}\right|^{1 / 2}} \exp \left[-\frac{1}{2}\left(\mathbf{d}-\mathbf{d}_{o b s}\right)^{T} \Sigma_{d}^{-1}\left(\mathbf{d}-\mathbf{d}_{o b s}\right)\right] .
$$

Thus the likelihood function $\mathbb{L}(\mathbf{m})$ (from Eqs. 2 and 3) is given as:

$$
\mathbb{L}(\mathbf{m}) \propto \exp \left[-\frac{1}{2}\left(G(\mathbf{m})-\mathbf{d}_{o b s}\right)^{T} \Sigma_{d}^{-1}\left(G(\mathbf{m})-\mathbf{d}_{o b s}\right)\right] .
$$

\subsubsection{Prior probability distribution}

The prior probability distribution $\rho_{M}(\mathbf{m})$ (or simply prior) can be some physical knowledge we have about the model parameters, e.g., from some independent sources. Due to lack of a priori physical knowledge and to reduce complexity, the prior has usually been chosen as an uninformative prior distribution (Fukuda \& Johnson 2008, 2010; Xu et al. 2015). However, informative priors can be very useful as they reduce the solution space of the model parameters and can exclude unphysical model solutions. We use information about the moment magnitude of the mainshock and locations of the aftershocks as informative priors to constrain the fault parameters of the Fukuoka earthquake. For ease in the sections later, we divide the fault parameters in $\mathbf{m}$ into two groups, parameters $\mathbf{m}_{1}$ that control the fault-slip and dimensions of the fault, and parameters $\mathbf{m}_{2}$ that control the location of the fault $\left(\mathbf{m}=\mathbf{m}_{1} \cup \mathbf{m}_{2}\right)$. 
(i) Moment magnitude: Due to the offshore location of the mainshock, the geodetic data do not constrain the dimensions of the fault well, leading to highly variable model solutions and large differences in the moment magnitude. By using a moment magnitude prior, we can restrict the fault models to a specified magnitude range and reject models with very high or very low moments. The moment magnitude in both the Global Centroid Moment Tensor (gCMT) catalog and USGS National Earthquake Information Center (NEIC) catalog is 6.6. Also, the mean of the moment magnitudes estimated previously using GPS and InSAR data (Nishimura et al. 2006; Ozawa et al. 2006), using strong motion data (Asano \& Iwata 2006; Kobayashi et al. 2006; Sekiguchi et al. 2006) and using broadband strong motion data (Suzuki \& Iwata 2006) is 6.6 (estimated from Table 1). Hence, the moment magnitude is considered to follow: $M_{w}\left(\mathbf{m}_{1}\right)+\epsilon_{2}=6.6$, where the error, $\epsilon_{2}$, is considered to be Gaussian with zero mean and variance of $h_{1}{ }^{2}$ (a hyperparameter that is estimated a priori and discussed later). The moment magnitude relates non-linearly to the fault model parameters: $M_{w}\left(\mathbf{m}_{1}\right)=\frac{2}{3} \log M_{o}\left(\mathbf{m}_{1}\right)-6.03$, where $M_{o}$ is the seismic moment in Nm given by $M_{o}\left(\mathbf{m}_{1}\right)=\mu \cdot L_{m} \cdot W_{m} \cdot s_{m}$, where $\mu$ is the material shear modulus (in Pa), $L_{m}$ and $W_{m}$ are respectively the fault length and width, and $s_{m}$ is the slip. We use a shear modulus of $32 \mathrm{GPa}$. Here, $M_{w}\left(\mathbf{m}_{1}\right)$ and $h_{1}$ are both dimensionless quantities. The moment magnitude prior PDF, $\rho\left(\mathbf{m}_{1}\right)$, is considered proportional to $\rho\left(M_{w}\left(\mathbf{m}_{1}\right)\right)=\mathcal{N}\left(6.6, h_{1}{ }^{2}\right)$ and is given as:

$$
\rho\left(\mathbf{m}_{1}\right) \propto \exp \left[-\frac{1}{2 h_{1}{ }^{2}}\left(M_{w}\left(\mathbf{m}_{1}\right)-6.6\right)^{2}\right] .
$$

(ii) Aftershock locations: The geometry and location of the fault plane can be estimated through non-linear optimization using geodetic data (Jónsson et al. 2002) or it can be estimated from aftershock locations (Custódio et al. 2009). In this study, we use geodetic data to estimate the fault geometry and use aftershock locations as an informative prior. This means that fault models that are not in accordance with the aftershock locations are more likely to be rejected during the MCMC sampling. We use precise locations of the aftershocks from Uehira et al. (2006) to define this informative prior. Considering there are $\mathrm{L}$ number of aftershock locations, we define a $L$-dimensional vector, $D\left(\mathbf{m}_{2}\right)$, which is comprised of the perpendicular distances between the aftershocks and the fault plane, $\mathbf{m}_{2}$ (Appendix A). Here, $D\left(\mathbf{m}_{2}\right)$ follows the relation: $D\left(\mathbf{m}_{2}\right)=\epsilon_{3}$, where $\epsilon_{3}$ is the L-dimensional random error. We assume this error to follow a Gaussian distribution with null-vector mean and variance of $h_{2}{ }^{2} \Sigma_{l}$, where $\Sigma_{l}$ is a diagonal matrix that incorporates the errors in the aftershock locations and $h_{2}{ }^{2}$ is a hyperparameter. Here, the unit of $D\left(\mathbf{m}_{2}\right)$ is $m$, that of $\Sigma_{l}$ is $m^{2}$, and $h_{2}$ is a dimensionless quantity. The aftershock locations prior $\operatorname{PDF} \rho\left(\mathbf{m}_{2}\right)$ is considered proportional to $\rho\left(D\left(\mathbf{m}_{2}\right)\right)=\mathcal{N}\left(\mathbf{0}, h_{2}{ }^{2} \Sigma_{l}\right)$ and is defined as follows:

$$
\rho\left(\mathbf{m}_{2}\right) \propto \exp \left[-\frac{1}{2 h_{2}{ }^{2}} D\left(\mathbf{m}_{2}\right)^{T} \Sigma_{l}^{-1} D\left(\mathbf{m}_{2}\right)\right] .
$$


The model prior PDF $\rho_{M}(\mathbf{m})$ (in Eq. 1) can thus be represented by the multiplication of the moment magnitude prior PDF $\rho\left(\mathbf{m}_{1}\right)$ and aftershock locations prior PDF $\rho\left(\mathbf{m}_{2}\right)$ as they are independent of each other. The moment magnitude prior PDF constrains the slip and dimensional parameters of the fault, while the aftershock locations prior PDF constrains the location parameters of the fault. Thus we have:

$$
\rho_{M}(\mathbf{m})=\rho\left(\mathbf{m}_{1}\right) \rho\left(\mathbf{m}_{2}\right) .
$$

\subsubsection{Posterior probability distribution}

From the definitions of the different terms given in Eqs. 1, 4, 5, 6 and 7, the posterior PDF of the model $\sigma_{M}(\mathbf{m})$ can be given as:

$$
\begin{aligned}
\sigma_{M}(\mathbf{m}) \propto \exp \left[-\frac{1}{2}(\right. & \left.G(\mathbf{m})-\mathbf{d}_{o b s}\right)^{T} \Sigma_{d}^{-1}\left(G(\mathbf{m})-\mathbf{d}_{o b s}\right) \\
& -\frac{1}{2 h_{1}{ }^{2}}\left(M_{w}\left(\mathbf{m}_{1}\right)-6.6\right)^{2} \\
& \left.-\frac{1}{2 h_{2}{ }^{2}} D\left(\mathbf{m}_{2}\right)^{T} \Sigma_{l}^{-1} D\left(\mathbf{m}_{2}\right)\right] .
\end{aligned}
$$

Using $H_{1}{ }^{2}=1 / h_{1}{ }^{2}, H_{2}{ }^{2}=1 / h_{2}{ }^{2}$ and a function $f(\mathbf{m})$, which is defined as:

$f(\mathbf{m})=\left[\left(G(\mathbf{m})-\mathbf{d}_{o b s}\right)^{T} \Sigma_{d}^{-1}\left(G(\mathbf{m})-\mathbf{d}_{o b s}\right)+H_{1}{ }^{2}\left(M_{w}\left(\mathbf{m}_{1}\right)-6.6\right)^{2}+H_{2}{ }^{2}\left(D\left(\mathbf{m}_{2}\right)^{T} \Sigma_{l}^{-1} D\left(\mathbf{m}_{2}\right)\right]\right.$,

we can rewrite the posterior probability distribution as

$$
\sigma_{M}(\mathbf{m}) \propto \exp \left[-\frac{1}{2}(f(\mathbf{m}))\right] .
$$

\subsubsection{Estimation of hyperparameters}

In Eq. $9, H_{1}^{2}$ and $H_{2}^{2}$ are the hyperparameters that control the relative weight of the corresponding prior with respect to the data. Using informative priors in the Bayesian framework requires estimation of these hyperparameters. For indirect prior constraints (for eg., fault slip smoothness constraint in distributed fault-slip estimation), the hyperparameters have been objectively estimated either by using Akaike's Bayesian Information Criterion (ABIC) (Akaike 1980; Funning et al. 2014; Yabuki \& Matsu'ura 1992) or by including them as additional parameters in the Bayesian inference (Fukuda \& Johnson 2008, 2010). In the case of direct prior constraints (for eg., bounds on the model parameter space) that relate either linearly (Hashimoto et al. 2009; Jackson 1979; Matsu'ura et al. 2007) or non-linearly (Matsu'ura \& Hasegawa 1987) to the model parameters, the hyperparameters have been chosen based on the prior information. Here, the direct prior constraints are non-linearly related to 
the model parameters and the hyperparameters are subjectively chosen based on a priori information about the fault models.

The variance of the Gaussian magnitude prior distribution (in Eq. 5), $h_{1}^{2}\left(=1 / H_{1}{ }^{2}\right)$, is estimated from the moment magnitudes reported in previous fault solutions (Table 1). The standard deviation of the moment magnitudes reported by previous researchers and agencies is estimated to be 0.0634 and this value is allocated as the standard deviation of the prior distribution $\left(h_{1}\right)$. The hyperparameter, $H_{1}{ }^{2}$, thus assigned in Eq. 8, is 248.78. The hyperparameter $H_{2}{ }^{2}\left(=1 / h_{2}{ }^{2}\right)$ is estimated from the characteristics of the aftershock locations. The aftershock locations are used to estimate the bestfitting plane and its uncertainties using Bayesian inference (Appendix B). From this best-fitting plane and its uncertainties, the distribution of $D(\mathbf{m})^{T} \Sigma_{L}^{-1} D(\mathbf{m})$ (in Eq. 6 and Fig. A2) is estimated and the standard deviation of this distribution is used as the standard deviation of the aftershock Gaussian prior distribution ( $h_{2}$ in Eq. 6). The hyperparameter, $\mathrm{H}_{2}{ }^{2}$, thus assigned in Eq. 8, is 0.00281 .

\subsubsection{Sampling algorithm}

To obtain information about a single model parameter $m_{k}$, we have to compute the corresponding 1D marginal posterior PDF for that parameter by integrating the full posterior PDF (in Eq. 10) over the entire model parameter space, except for the model parameter of interest:

$$
M_{\text {marg }}\left(m_{k}\right)=\int_{-\infty}^{\infty} \cdots \int_{-\infty}^{\infty} \sigma_{M}(\mathbf{m}) \prod_{i=1}^{M} d m_{i} .
$$

Due to the multi-dimensionality of the posterior PDF, we can generate samples from it using a Monte Carlo method to approximately obtain the above marginal PDF. We use one of the MCMC techniques, the Metropolis algorithm (Metropolis et al. 1953), to obtain a sequence of random model samples of the posterior PDF. In this method, each candidate model sample is generated by a random walk that depends only on the previous model sample. The procedure of this algorithm can be described as:

(i) Suppose $\mathbf{x}^{(i)}$ is the initial model sample, $g(\mathbf{x})$ is the target distribution that needs to be sampled and $q\left(\mathbf{x} \mid \mathbf{x}^{(i)}\right)$ is the proposal distribution used to generate a model sample from the initial model sample.

(ii) Generate a model sample $\mathbf{x}^{*}$ from the previous candidate model sample $\mathbf{x}^{(i)}$ using the proposal distribution $\mathbf{x}^{*} \sim q\left(\mathbf{x} \mid \mathbf{x}^{(i)}\right)$. We use a multi-dimensional Gaussian proposal distribution $q\left(\mathbf{x} \mid \mathbf{x}^{(i)}\right)$ with mean $\mathbf{x}^{(i)}$ and standard deviation $1 / 10^{t h}$ of the range of the corresponding model parameter space. 
(iii) Calculate the acceptance probability, $\varphi\left(\mathbf{x}^{(i)}, \mathbf{x}^{*}\right)$, from the relation

$$
\varphi\left(\mathbf{x}^{(i)}, \mathbf{x}^{*}\right)=\min \left[1, \frac{g\left(\mathbf{x}^{*}\right)}{g\left(\mathbf{x}^{(i)}\right)} \frac{q\left(\mathbf{x}^{(i)} \mid \mathbf{x}^{*}\right)}{q\left(\mathbf{x}^{*} \mid \mathbf{x}^{(i)}\right)}\right]
$$

Since the proposal distribution is symmetric (Gaussian), then $q\left(\mathbf{x}^{*} \mid \mathbf{x}^{(i)}\right)=q\left(\mathbf{x}^{(i)} \mid \mathbf{x}^{*}\right)$.

(iv) Set the next candidate model sample, $\mathbf{x}^{(i+1)}=\mathbf{x}^{*}$, with probability $\varphi\left(\mathbf{x}^{(i)}, \mathbf{x}^{*}\right)$, otherwise set $\mathbf{x}^{(i+1)}=\mathbf{x}^{(i)}$. The model sample $\mathbf{x}^{*}$ is always selected to be a candidate sample if $g\left(\mathbf{x}^{*}\right)>$ $g\left(\mathbf{x}^{(i)}\right)$, which means that the more probable model samples are always selected. If the move is towards a less probable model sample, the move is sometimes rejected, depending on the relative drop in probability. The larger the relative drop in probability is, the more likely it is that the next model sample is rejected. Thus, the algorithm preferentially samples high probability regions of the model space while occasionally sampling from low probability regions.

(v) Repeat the process from step (ii).

Using this algorithm, we generated 100000 samples from 10 independent chains, each with a different initial model. The average acceptance rate was $\sim 27 \%$ for all the chains. The samples were tested for the convergence diagnostic using the Gelman and Rubin Multiple Sequence Diagnostic test (Gelman \& Rubin 1992) by calculating the potential scale reduction factor (PSRF) from the withinchain and between-chain variance (see Supp. 3). PSRF close to 1 indicates that the chains converged to a stationary distribution and that the samples drawn represent the posterior distribution. The first $20 \%$ of the samples of each chain, corresponding to a burn-in period, were removed and then the sample chains were thinned to 8000 samples to reduce sample correlation (Fig. S2).

\subsubsection{Error statistics}

We derived the data error of the continuous GPS displacements from standard deviations of daily coordinate solutions, which yielded a 1-6 mm error in the horizontal displacements and a 4-15 mm error in the vertical displacements. The errors in the campaign GPS data are larger, about $50 \mathrm{~mm}$ and $100 \mathrm{~mm}$ for the horizontal and vertical components of the displacements, respectively. The relative weights of the campaign and continuous GPS are $7.5 \%$ and $92.5 \%$, respectively.

Observational errors in InSAR data may result from various sources, for example from noise at the radar instrument, the propagation of radar waves, from reflecting surfaces, and from processing of the radar images (Hanssen 2001). While some of these errors can be removed or reduced during the data processing of the images, spatially correlated errors caused by atmospheric delays (Sudhaus \& Jónsson 2009; Knospe \& Jónsson 2009; Lohman \& Simons 2005) are difficult to remove. These errors are smoothly varying in space and can have amplitudes of few centimeters and sometimes comparable 
spatial patterns to the expected deformation signals. In our study, we characterize these errors by a stochastic model of the structure of variability (Knospe \& Jónsson 2009). We formed an empirical covariogram using areas where coseismic displacement was not expected. We then consider the error statistics in this area to represent that of the whole interferogram (stationarity). The resulting empirical isotropic covariogram is a function of data values separated by a distance (lag), $h$, in all directions:

$$
\mathcal{C}(h)=\frac{1}{2 N} \sum_{\substack{i=1 \\\left|\mathbf{r}_{i}-\mathbf{s}_{i}\right| \simeq h}}^{N} d\left(\mathbf{r}_{i}\right) \cdot d\left(\mathbf{s}_{i}\right) .
$$

We then fitted to this empirical covariogram a positive definite covariance function of the form $\mathcal{C}_{f}(h)=$ $a \cdot \cos ((h+b) / c) \cdot \exp (-h / e)$, where $\mathcal{C}_{f}$ is the covariance between data-points with a lag distance $h$ (Fig. 2d). This covariance function is used to determine the variance-covariance matrix of the full resolution data $\left(\Sigma_{c}\right)$. The variance-covariance matrix for the subsampled data, $\Sigma_{d}$ (in Eq. (4)), is then obtained from the transformation of the variance-covariance matrix of the full resolution data, $\Sigma_{d}$ : $\Sigma_{d}=A \Sigma_{c} A^{T}$, where the operator, $A$, relates the subsampled data, $\mathbf{d}$, to the full data vector $\mathbf{d}_{c}$ as $\mathbf{d}=A \mathbf{d}_{c}$. The relative weights of the GPS, track 17 point-target InSAR and track 246 InSAR datasets are $34.9 \%, 16.2 \%$ and $48.8 \%$, respectively.

\section{RESULTS}

In this section, we present the results of the Bayesian estimation using informative priors. Fig. 4(a) shows the 1D and 2D marginal posterior PDFs of the model parameters obtained from the ensemble of models that were sampled. As expected, the data constrain the eastern end of the fault better than they constrain its western end (Fig. 4b). The 95\% confidence ellipse for the location of the fault's western end has a length of $9 \mathrm{~km}$, whereas the ellipse for the location of the fault's eastern end is 5 $\mathrm{km}$. This reflects the fact that the data coverage is much better east of the earthquake (see Fig. 2a). The 1D posterior distribution of the fault length shows high probability at 11-14 km (Fig. 5), which is somewhat shorter than what the aftershocks indicate (Fig. 3) and is influenced by the uniform-slip parameterization of the fault. The end-point locations of the fault correlate with the amount of leftlateral fault-slip such that longer faults have less slip and smaller faults have more slip. The uniform left-lateral strike slip varies from 1.2-3 m.

The depth of the fault is shallow and fault models that rupture the sea-floor explain the data better. The depth correlates strongly with the fault width with deeper faults having smaller widths. The 1D posterior distribution for fault width peaks at $\sim 14 \mathrm{~km}$. The fault is close to vertical with the fault dip ranging from $85^{\circ}$ to $95^{\circ}$ to the southwest and peaking at $\sim 90^{\circ}$ (vertical fault). The uniform left-lateral slip correlates with most parameters that control the location of the fault. The moment magnitude 
discerned from the marginal posterior PDF (see Fig. 4) varies from 6.54 to 6.6 with a peak at 6.568 , whereas the moment magnitude prior was centered at 6.6 with a standard deviation of 0.0634 . The maximum a posteriori (MAP) values of most of the fault parameters (red line in 1D marginal PDFs in Fig. 4) are similar to the posterior mode values of those parameters. The posterior mean values (green dashed lines in Fig. 4), on the other hand, are somewhat different than the MAP values, especially for the fault width, depth and slip. Fig. 3 shows the different datasets, predicted data from the MAP model and the residuals.

\subsection{Effect of informative priors}

As discussed above, we used informative a priori constraints on the fault model parameters due to the limited coverage of the geodetic data in our study. Here, we examine the effect that these informative priors have on the estimation. Fig. 5 shows the 1D marginal posterior distributions of the fault model parameters for four different cases: use of uniform (uninformative) priors, use of a magnitude prior, use of an aftershock locations prior and use of both magnitude and aftershock locations priors.

The peak of the magnitude marginal distribution shifts from 6.546 to 6.568 when the moment magnitude prior is added, but this prior does not much affect other posterior marginals of the fault parameters (Fig. 5). This is due to the fact that the data, though sparse, are capable of estimating the moment magnitude with an uncertainty that is one-tenth of a unit (Fig. 5a) and that a moment magnitude prior with larger standard deviation than the moment magnitude estimate has limited effect in the estimation. Using this prior is more effective when the data errors are high and the estimation is less certain (Xu et al. 2015).

In contrast, the marginal distributions of most of the fault-slip model parameters when using the aftershock locations prior are systematically different from the results that do not include that prior. When using the aftershocks prior, the length of the fault is smaller and the uniform left-lateral slip is larger. The distribution for fault strike shows that the aftershock locations prior leads to a tighter constraint on strike, which peaks at $\sim 120^{\circ}$. The fault parameters that control the fault strike in our parameterization, i.e., the easting and northing of the ends of the fault are less variable than without this prior (see Fig. 5). Due to the offshore location of the earthquake and lack of the near-field geodetic data, the constraint on the strike is biased. The aftershock locations thus clearly help to constrain the strike of the fault.

When using both the moment magnitude and aftershock locations priors, most of the resulting fault parameters are similar to the case when only the aftershock locations prior is used. However, the use of both priors tends to result in tighter constraints on the model parameters, e.g., for fault strike, than when only geodetic data are used (i.e., without priors). 


\subsection{Propagation of errors in the calculation of Coulomb Failure Stress changes}

To propagate the fault model with uncertainties to Coulomb Failure Stress changes ( $\Delta$ CFS), we calculated the $\triangle \mathrm{CFS}$ for the ensemble of models that we obtained from sampling the posterior PDF. We calculated the $\triangle \mathrm{CFS}$ for the left-lateral strike slip on receiver faults that have similar strikes as the Kego fault. The mean of the $\triangle$ CFS shows an increase in stress on the Kego fault (Fig. 6a) indicating that the Fukuoka earthquake pushed the Kego fault closer to failure. The standard deviation of the $\triangle \mathrm{CFS}$ values shows that the variability of the $\triangle \mathrm{CFS}$ is high close to the source fault but decays rapidly with distance (Fig. 6b). The coefficient of variation map has high values close to the fault and at the edges between positive and negative $\triangle$ CFS lobes (Fig. 6c). Thus, the coefficient of variation is high in the regions where the standard deviation is high (close to the fault) or where the mean $\Delta \mathrm{CFS}$ is low.

The variability of estimated $\Delta$ CFS differs significantly between locations. On Genkai Island (Location 1 in Fig. 6c), which is located close to the source fault where the coefficient of variation of $\triangle \mathrm{CFS}$ is high, the $\triangle \mathrm{CFS}$ ranges from -4 to $3 \mathrm{MPa}$. Estimates of $\triangle \mathrm{CFS}$ values at such locations near the end of a source fault are usually unreliable as a small change in fault strike can lead to a sign change of the resulting $\triangle \mathrm{CFS}$ value. Nishinoura (Location 3) and Shika Island (Location 4) both lie in areas where the coefficient of variation is lower $(\sim 0.2)$ and the $95 \%$ confidence interval of the $\Delta \mathrm{CFS}$ at these locations shows an uncertainty of less than $1 \mathrm{MPa}$. The Kego fault in Fukuoka city (Location 2) exhibits very low variability with the $95 \%$ confidence interval having a width of only $0.025 \mathrm{MPa}$. The entire distribution of $\triangle \mathrm{CFS}$ at this location is positive and peaks at $\sim 0.11 \mathrm{MPa}$, indicating that all the fault models of the ensemble predict positive $\triangle \mathrm{CFS}$ on the Kego fault. If the Kego fault extends offshore toward the source fault, then the $\triangle \mathrm{CFS}$ increase there is even more significant. This is a future concern for Fukuoka city and its current population of more than 1.5 million.

We find that the aftershock locations informative prior affects $\Delta$ CFS variations, as the location of positive and negative lobes of $\triangle \mathrm{CFS}$ are sensitive to the strike of the fault. The high variation region of $\triangle \mathrm{CFS}$ that lies along the edges of these lobes can be misplaced if the fault strikes are biased in the fault model estimation (Fig. 5b). As in our case, the strike is constrained better at $\sim 120^{\circ}$ thus reducing the variation of $\triangle \mathrm{CFS}$ in such regions. The $\triangle \mathrm{CFS}$ variations at Genkai Island, Shika Island, Nishinoura and Kego fault (Fukuoka city) are lower when using the priors as compared to when not using the priors (Fig. 7). In addition, the $\triangle \mathrm{CFS}$ values are systematically higher on the Kego fault (Fukuoka city) and under Shika Island when using the informative priors (Fig. 7b and d). 


\section{DISCUSSION}

Many studies have been published on the source parameters of the Fukuoka earthquake as described in Section 2, although all were published without estimated uncertainties. When we compare our fault model parameter results of the earthquake with previous source estimations, we find that some published model parameters fall outside of the error bounds we have estimated (Fig. 8). For example, the NEIC and gCMT centroid locations lie $8 \mathrm{~km}$ northwest and $3 \mathrm{~km}$ southwest from our solution, respectively, and well outside our 95\% confidence ellipse (Fig. 8a). In addition, in all the studies (except one) that used strong motion, GPS and InSAR data to estimate the variable slip distribution, the centroid locations (and the slip asperities) lie southeast of our solution. Only NIED-Fnet and Ito et al. (2006) have centroid locations within our $95 \%$ confidence bounds. The centroid depths of reported solutions also differ considerably, ranging from 10-12 km (gCMT, NEIC, NIED F-net and Ito et al. 2006) to shallower depths of 4-6 km (Sekiguchi et al. 2006; Ozawa et al. 2006; Kobayashi et al. 2006). The minimum allowed fault depth in the moment tensor solutions (gCMT, NEIC and NIED F-net) is generally 10-12 km (Ekström et al. 2012) and hence their fault depth estimates are higher (2-4 km) than the estimates in our study. It is interesting to note that although the aftershock locations prior in our study constrains the fault strike and fault dip, but it does not constrain the fault depth. This is because the aftershock locations are used to constrain an infinite fault-plane and thus several vertical fault planes with varying depth that can be subsets of such an infinite fault plane would all have the same aftershock locations prior probability (due to same value of $D(\mathbf{m})$ in Eq. 6).

Some of the slip distributions reported in previous studies have more than one slip asperity (Asano \& Iwata 2006; Horikawa 2006; Sekiguchi et al. 2006). Multiple asperities at different depths are generally not constrained well from geodetic data alone (e.g., Pedersen et al. 2003) except for larger earthquakes. Also, fault models using geodetic data have lower resolution for slip at increasing depths. Hence, we simply used a uniform dislocation fault model in this study as the sparse geodetic data do not resolve more than one slip maximum. Moreover, variable and uniform slip models predict similar $\Delta$ CFS values at distances far from the fault (Steacy et al. 2005). However, using a uniform slip model results in a fault with a shorter length as observed in Section 5.

The moment magnitude estimated in our study peaks at 6.568 and only four solutions lie within the $95 \%$ error of our solution. Horikawa (2006) presents an estimate lower than our solution, while other solutions have a slightly higher moment magnitude. The fault strike is well determined in our estimation using the aftershock location prior and peaks at $\sim 120^{\circ}$ with a standard deviation of only $\sim 1.5$ degrees (Fig. 8c). The reported solutions (except for one) have a slightly larger strike value and about half of the solutions lie outside the $1-\sigma$ of our results. The fault dip determined is near vertical, dipping slightly to the southwest (Fig. 8d). Most of the published solutions have a similar dip and are 
within the error bounds, except the NEIC solution dips $63^{\circ}$ to the southwest and that of Nishimura et al. (2006) dips $79^{\circ}$ to the southwest.

We have shown the importance of priors in our study and proposed a way to estimate hyperparameters, which determine the relative weight between the corresponding prior and the likelihood function. Often, during estimation of slip distribution, slip smoothness priors were used as a regularization term (Jónsson et al. 2002; Wright et al. 2004) or as an indirect prior PDF (Fukuda \& Johnson $2008,2010)$ to penalize high slip variations between nearby slip patches. The smoothing/roughness parameter (hyperparameter) has usually been obtained from a trade-off curve of the roughness norm against a weighted residual norm (Du et al. 1992; Jónsson et al. 2002). A solution was then selected at a roughness parameter value where it falls at the center of the bend of the curve. Fukuda \& Johnson (2008) showed that the location of where such a trade-off curve bends depends on the scaling of the plot axes and thus the choice of roughness parameter may vary with changes in axes scaling. Hence, Fukuda \& Johnson (2008) estimated it objectively by sampling the hyperparameter using Bayesian inference, where the hyperparameter that maximized the posterior distribution was chosen. Fukahata \& Wright (2008) used Akaike's Bayesian Inference Criterion (ABIC) to select the hyperparameters that minimizes the effective cost function by minimizing ABIC and thereby maximizing the marginal likelihood. The estimation of hyperparameters in all of these cases is dependent on the geodetic data and would be affected by changes in the data and their uncertainties. These techniques can be useful when information on the characteristics of the priors is limited or is dependent on the forward model. In contrast, The hyperparameters in our study are not dependent on the forward model and can be estimated solely based on the properties of the prior information. The hyperparameters thus selected are not affected by the geodetic data and their uncertainties.

We estimate the uncertainty of the coseismic $\triangle \mathrm{CFS}$ at a few locations and observe that $\triangle \mathrm{CFS}$ can have a multi-modal distribution at particular locations and can vary greatly depending on the location around the source fault (Fig. 7a). Thus, a single optimum estimate of the $\Delta$ CFS usually reported by authors can be misleading. The $\Delta \mathrm{CFS}$ estimated at two locations (Locations 2 and 4 in Fig. 7) on the Kego fault are found to be 0.1-0.13 MPa and 0.4-1.0 MPa, respectively. Stein et al. (1997) inferred that nine of the ten earthquakes that occurred on the North Anatolian fault from 1939-1992 were brought closer to failure by the preceding earthquakes, typically by $\triangle \mathrm{CFS}$ of 0.1-1.0 MPa. When secular stress accumulation was included along with coseismic stress change, the mean $\triangle \mathrm{CFS}$ over the entire future rupture increased by 0.2-0.4 MPa for nine of the ten earthquakes. A similar stress evolution study by Doser \& Robinson (2002) showed that six of the seven earthquakes occurring in the Southern Marlborough region (New Zealand) from 1888 to 1994 might have been triggered due to increased $\triangle \mathrm{CFS}$ (coseismic and secular stress accumulation) of $0.06-0.5 \mathrm{MPa}$ after the previous 
earthquake. These studies imply that the stress changes caused by the 2005 Fukuoka earthquake on the Kego fault are large enough to significantly advance the next earthquake on that fault. In addition, better information about the interseismic loading rate and stress changes on the Kego fault would improve seismic hazard assessment for Fukuoka city and its surroundings.

\section{CONCLUSIONS}

In this paper, we have shown how to include a priori information, such as the mainshock magnitude and aftershock locations, when constraining earthquake source parameters in Bayesian estimation. This can be useful in cases where geodetic data are limited and do not constrain the fault geometry well. In particular, the aftershock locations prior helps in better constraining the location and strike of the fault. We estimate the hyperparameters that control the weight of a priori information with respect to the likelihood function from the uncertainty of the prior information. This allows the hyperparameters to be independent of the geodetic data and their uncertainties.

Applying this framework to the $2005 M_{W} 6.6$ Fukuoka earthquake, we have shown how certain fault model parameters got adjusted to fulfill the a priori constraints, e.g., fault strike lined up with the aftershock distribution after including the aftershock location information. We propagated the estimated fault model parameters with uncertainties to calculations of $\triangle \mathrm{CFS}$, focusing on the Kego fault in Fukuoka city, which is thought to be an extension of the fault activated in the earthquake. We observe that the variability of $\triangle \mathrm{CFS}$ on the Kego fault is lower when using the priors as against when not using the priors. The results show that the $\triangle \mathrm{CFS}$ on the Kego fault is strongly positive and hence a concern for the over 1.5 million people living in Fukuoka.

\section{ACKNOWLEDGMENTS}

We thank Shin'ichi Miyazaki (Kyoto Univ.) for discussions and the Earthquake Research Institute (Univ. Tokyo) for hosting SJ during the early part of this work. Comments from Yukitoshi Fukahata (Kyoto Univ.) and an anonymous reviewer improved the manuscript. We thank Chiheb Hammouda (KAUST) for fruitful discussions. The ENVISAT data were provided by the European Space Agency through category-1 project 3639. Generic Mapping Tools (GMT) were used to make Figure 1. This research was supported by King Abdullah University of Science and Technology (KAUST).

\section{REFERENCES}

Akaike, H., 1980, Likelihood and the Bayes procedure, Trabajos de Estadistica Y de Investigacion Operativa, 31(1), 143-166. 
Asano, K. \& Iwata, T., 2006, Source process and near-source ground motions of the 2005 West Off Fukuoka Prefecture earthquake, Earth Planets Space, 58(1), 9398.

Cervelli, P., Murray, M.H., Segall, P., Aoki, Y. \& Kato, T., 2001, Estimating source parameters from deformation data, with an application to the March 1997 earthquake swarm off the Izu Peninsula, Japan, J. geophys. Res., 106(B6), 11217-11237.

Chen, C.W. \& Zebker, H.A., 2002, Phase unwrapping for large SAR interferograms: statistical segmentation and generalized network models, IEEE T. Geosci. Remote, 40(8), 1709-1719.

Custódio, S., Page, M.T., \& Archuleta, R.J., 2009, Constraining earthquake source inversions with GPS data: 2. A two-step approach to combine seismic and geodetic data sets, J. geophys. Res., 114(B1).

Deng, J., \& Sykes, L.R., 1997, Stress evolution in southern California and triggering of moderate-, small-, and micro-size earthquakes, J. geophys. Res., 102(B11), 24411-24435.

Doser, D.I. \& Robinson, R., 2002, Modeling stress changes induced by earthquakes in the Southern Marlborough region, South Island, New Zealand, Bull. seism. Soc. Am., 92(8), 3229-3238.

Du, Y., Aydin, A. \& Segall, P., 1992, Comparison of various inversion techniques as applied to the determination of a geophysical deformation model for the 1983 Borah Peak earthquake, Bull. seism. Soc. Am., 82(4), 1840-1866.

Duputel, Z., Agram, P.S., Simons, M. \& Minson, S.E., 2014, Accounting for prediction uncertainty when inferring subsurface fault slip, Geophys. J Int., 197(1), 464-482.

Ekström, G., Nettles, M. \& Dziewoński, A.M., 2012, The global CMT project 2004-2010: Centroid-moment tensors for 13,017 earthquakes, Phys. Earth Planet. Inter, 200-201, 1-9.

Farr, T.G., Rosen, P.A., Caro, E., Crippen, R., Duren, R., Hensley, S., Kobrick, M., Paller, M., Rodriguez, E., Roth, L., Seal, D., Shaffer, S., Shimada, J., Umland, J., Werner, M., Oskin, M., Burbank, D. \& Alsdorf, D., 2007, The shuttle radar topography mission, Rev. Geophys., 45, RG2004.

Fukahata, Y. \& Wright, T.J., 2008, A non-linear geodetic data inversion using ABIC for slip distribution on a fault with an unknown dip angle, Geophys. J Int., 173, 353-364.

Fukuda, J. \& Johnson, K.M., 2008, A fully Bayesian inversion for spatial distribution of fault slip with objective smoothing, Bull. seism. Soc. Am., 98(3), 1128-1146.

Fukuda, J. \& Johnson, K.M., 2010, Mixed linear-non-linear inversion of crustal deformation data: Bayesian inference of model, weighting and regularization parameters, Geophys. J Int., 181(3), 1441-1458.

Funning, G.J., Barke, R.M.D., Lamb, S.,H., Minaya, E., Parsons, B. \& Wright, T.J., 2005, The 1998 Aiquile, Bolivia earthquake: A seismically active fault revealed with InSAR, Earth Planet. Sci. Lett., 232(1-2), 39-49. Funning, G.J., Fukahata, Y., Yagi, Y. \& Parsons, B., 2014, A method for the joint inversion of geodetic and seismic waveform data using ABIC: application to the 1997 Manyi, Tibet, earthquake, Geophys. J Int., 203(2).

Gelman, A. \& Rubin, D.B., 1992, Inference from iterative simulation using multiple sequences, Statistical Science, 7(4), 457-511.

Goldstein, R.M. \& Werner, C.L., 1998, Radar interferogram filtering for geophysical applications, Geophys. Res. Lett., 25(21), 40354038. 
Hainzl, S., Enescu, B., Cocco, M., Woessner, J., Catalli, F., Wang, R. \& Roth, F., 2009, Aftershock modeling based on uncertain stress calculations, J. geophys. Res., 114(B5).

Hanssen, R.F., 2001, Radar Interferometry: Data Interpretation and Error Analysis, Kluwer Academic Publishers.

Hardebeck, J.L. \& Michael, A.J., 2006, Damped regional-scale stress inversions: Methodology and examples for southern California and the Coalinga aftershock sequence, J. geophys. Res., 111(B11).

Harris, R.A., 1998, Introduction to special section: Stress triggers, stress shadows, and implications for seismic hazard, J. geophys. Res., 103(B10), 24347-24358.

Hashimoto, C., Noda, A., Sagiya, T. \& Matsu'ura, M., 2009, Interplate seismogenic zones along the KurilJapan trench inferred from GPS data inversion, Nat. Geosci., 2, 141-144.

Hincapie, J.O., Doser, D.I. \& Robinson, R., 2005, Stress changes induced by earthquakes and secular stress accumulation in the Buller region, South Island, New Zealand (1929-2002), Pure Appl. Geophys.,162(2), 291-310.

Hodgkinson, K.M., Stein, R.S. \& King, G.C.P., 1996, The 1954 Rainbow Mountain-Fairview Peak-Dixie Valley earthquakes: A triggered normal faulting sequence, J. geophys. Res., 101(B11), 25459-25471.

Horikawa, H., 1996, Rupture process of the 2005 West Off Fukuoka Prefecture, Japan, earthquake, Earth Planets Space, 58(1), 87-92.

Ito, Y., Obara, K., Takeda, T., Shiomi, K., Matsumoto, T., Sekiguchi, S. \& Hori, S., 2006, Initial-rupture fault, main-shock fault, and aftershock faults: Fault geometry and bends inferred from centroid moment tensor inversion of the 2005 west off Fukuoka prefecture earthquake, Earth Planets Space, 58, 69-74.

Jackson, D.D., 1979, The use of a priori data to resolve non-uniqueness in linear inversion, Geophys. J. R. astr. Soc., 57, 137-157.

Jónsson, S., Zebker, H., Segall, P. \& Amelung, F., 2002, Fault slip distribution of the 1999 Mw 7.1 Hector Mine, California, earthquake, estimated from satellite radar and GPS measurements, Bull. seism. Soc. Am., 92(4), 1377-1389.

Karakida, Y., Tomita, S., Simoyama, S. \& Chijiwa, K., 1994, Geology of the Fukuoka district with geological sheet map at 1:50,000. Geological Survey of Japan, 1-192 (in Japanese with English abstract).

King, G.C.P., Stein, R.S. \& Lin, J., 1994, Static stress changes and the triggering of earthquakes, Bull. seism. Soc. Am., 84(3), 935-953.

Knospe, S., \& Jónsson, S., 2009, Covariance estimation for dInSAR surface deformation measurements in the presence of anisotropic atmospheric noise, IEEE T. Geosci. Remote, 48(4), 2057-2065.

Kobayashi, R., Miyazaki, S. \& Koketsu, K., 2006, Source processes of the 2005 West Off Fukuoka Prefecture earthquake and its largest aftershock inferred from strong motion and 1-Hz GPS data, Earth Planets Space,58(1), 57-62.

Lin, J. \& Stein, R.S., 2004, Stress triggering in thrust and subduction earthquakes and stress interaction between the southern San Andreas and nearby thrust and strike-slip faults, J. geophys. Res., 109(B2), B02303.

Lohman, R.B. \& Simons, M., 2005, Locations of selected small earthquakes in the Zagros mountains, 
Geochem. Geophys. Geosyst., 6(1), Q03001.

Lohman, R.B. \& Barnhart, W.D., 2010, Evaluation of earthquake triggering during the 2005-2008 earthquake sequence on Qeshm Island, Iran, J. geophys. Res., 115(B12), B12413.

Matsumoto, T., Ito, Y., Matsubayashi, H. \& Sekiguchi, S., 2006, Spatial distribution of F-net moment tensors for the 2005 West Off Fukuoka Prefecture Earthquake determined by the extended method of the NIED F-net routine, Earth Planets Space,58(1), 63-67.

Matsumoto, S., Uehira, K., Matsushima, T. \& Shimizu, H., 2012, Modeling heterogeneous deviatoric stress field around the hypocentral area of the 2005 Fukuoka earthquake (M7.0) by spatially distributed moment tensors, J. geophys. Res., 117(B3), B03303.

Matsu'ura, M. \& Hasegawa, Y., 1987, A maximum likelihood approach to nonlinear inversion under constraints, Phys. Earth Planet. Inter, 47, 179-187.

Matsu'ura, M., Noda, A. \& Fukahata, Y., 2007, Geodetic data inversion based on Bayesian formulation with direct and indirect prior information, Geophys. J Int., 171(3), 1342-1351.

Metropolis, N., Rosenbluth, A.W., Rosenbluth, M.N., Teller, A.H. \& Teller, E., 1953, Equation of State Calculations by Fast Computing Machines, J. Chem. Phys., 21(6), 1087.

Monelli, D., Mai, P.M., Jónsson, S. \& Giardini, D., 2009, Bayesian imaging of the 2000 Western Tottori (Japan) earthquake through fitting of strong motion and GPS data, Geophys. J Int., 176(1), 135-150.

Nalbant, S.S., Hubert, A. \& King, G.C.P., 1998, Stress coupling between earthquakes in northwest Turkey and the north Aegean Sea, J. geophys. Res., 103(B10), 2446924486.

Nishimura, T., Fujiwara, S., Murakami, M., Suito, H., Tobita, M. \& Yarai, H., 2006, Fault model of the 2005 Fukuoka-ken Seiho-oki earthquake estimated from coseismic deformation observed by GPS and InSAR, Earth Planets Space, 58(1), 51-56.

Okada, Y., 1985, Surface deformation due to shear and tensile faults in a half-space, Bull. seism. Soc. Am., 75(4), 1135-1154.

Ozawa, T., Nishimura, S. \& Ohkura, H., 2006, Crustal deformation associated with the 2005 west off Fukuoka Prefecture earthquake derived from ENVISAT/InSAR and fault- slip modeling, Report of the National Research Institute for Earth Science and Disaster Prevention, 69.

Parsons, T., Toda, S., Stein, R.S., Barka, A. \& Dieterich, J.H., 2000, Heightened odds of large earthquakes near Istanbul: An interaction-based probability calculation, Science, 288(5466), 661-665.

Parsons, T., Ji, C. \& Kirby, E., 2008, Stress changes from the 2008 Wenchuan earthquake and increased hazard in the Sichuan basin, Nature, 454, 509-510.

Pedersen, R., Jónsson, S., Árnadóttir, T., Sigmundsson, F. \& Feigl, K.L., 2003, Fault slip distribution of two June $2000 M_{w} 6.5$ earthquakes in South Iceland estimated from joint inversion of InSAR and GPS measurements, Earth Planet. Sci. Lett., 213(3-4), 487-502.

Sekiguchi, H., Aoi, S., Honda, R., Morikawa, N., Kunugi, T. \& Fujiwara, H., 2006, Rupture process of the 2005 West Off Fukuoka Prefecture earthquake obtained from strong motion data of K-NET and KiK-net, Earth Planets Space, 58(1), 37-43. 
Shimizu, H., Takahashi, H., Okada, T., Kanazawa, T., Iio, Y., Miyamachi, H., Matsushima, T., Ichiyanagi, M., Uchida, N., Iwasaki, T., Katao, H., Goto, K., Matsumoto, S., Hirata, N., Nakao, S., Uehira, K., Shinohara, M., Yakiwara, H., Kame, N., Urabe, T., Matsuwo, N., Yamada, T., Watanabe, A., Nakahigashi, K., Enescu, B., Uchida, K., Hashimoto, S., Hirano, S., Yagi, T., Kohno, Y., Ueno, T., Saito, M. \& Hori, M., 2007, Aftershock seismicity and fault structure of the 2005 West Off Fukuoka Prefecture Earthquake $\left(M_{J M A} 7.0\right)$ derived from urgent joint observations, Earth Planets Space, 58(12), 1599-1604.

Steacy, S., Nalbant, S.S., McCloskey, J., Nostro, C., Scotti, O. \& Baumont, D., 2005, Onto what planes should Coulomb stress perturbations be resolved?, J. geophys. Res., 110(B5), B05S15.

Stein, R.S., King, G.C.P. \& Lin, J., 1992, Change in failure stress on the southern San Andreas fault system caused by the 1992 magnitude = 7.4 Landers earthquake, Science, 258(5086), 1328-1332.

Stein, R.S., King, G.C.P. \& Lin, J., 1994, Stress triggering of the 1994 M = 6.7 Northridge, California, earthquake by its predecessors, Science, 265(5177), 1432-1435.

Stein, R.S., Barka, A.A. \& Dieterich, J.H., 1997, Progressive failure on the North Anatolian fault since 1939 by earthquake stress triggering, Geophys. J Int., 128(3), 594-604.

Sudhaus, H. \& Jónsson, S., 2009, Improved source modelling through combined use of InSAR and GPS under consideration of correlated data errors: application to the June 2000 Kleifarvatn earthquake, Iceland, Geophys. J Int., 176(2), 389-404.

Sudhaus, H. \& Jónsson, S., 2011, Source model for the 1997 Zirkuh earthquake $\left(M_{W}=7.2\right)$ in Iran derived from JERS and ERS InSAR observations, Geophys. J Int., 185(2), 676-692.

Sun, J., Johnson, K.M., Cao, Z., Shen, Z., Bürgmann, R. \& Xu, X., 2011, Mechanical constraints on inversion of coseismic geodetic data for fault slip and geometry: Example from InSAR observation of the 6 October 2008 Mw 6.3 Dangxiong-Yangyi (Tibet) earthquake, J. geophys. Res., 116(B1).

Suzuki, W. \& Iwata, T., 2006, Source model of the 2005 west off Fukuoka prefecture earthquake estimated from the empirical Greens function simulation of broadband strong motions, Earth Planets Space, 58(1), 99-104.

Takenaka, H., Nakamura, T., Yamamoto, Y., Toyokuni, G. \& Kawase, H., 2006, Precise location of the fault plane and the onset of the main rupture of the 2005 West Off Fukuoka Prefecture earthquake, Earth Planets Space, 58(1), 75-80.

Tarantola, A., 2005, Inverse Problem Theory and Methods for Model Parameter Estimation, Society for Industrial and Applied Mathematics, Philadelphia.

Uehira, K., Yamada, T., Shinohara, M., Nakahigashi, K., Miyamachi, H., Iio, Y., Okada, T., Takahashi, H., Matsuwo, N., Uchida, K., Kanazawa, T. \& Shimizu, H., 2006, Precise aftershock distribution of the 2005 West Off Fukuoka Prefecture Earthquake $(\mathrm{Mj}=7.0)$ using a dense onshore and offshore seismic network, Earth Planets Space, 58(12), 1605-1610.

Werner, C.L., Wegmüller, U., Strozzi, T. \& Wiesmann, A., 2000, Gamma SAR and interferometric processing software, ERS-ENVISAT Symposium, Eur. Space Agency, Gothenberg, Sweden.

Wright, T.J., Lu, Z. \& Wicks, C., 2004, Constraining the slip distribution and fault geometry of the $M_{W}$ 


\section{Dutta, R., Jónsson, S., Wang, T. \& Vasyura-Bathke, $H$.}

7.9, 3 November 2002, Denali fault earthquake with Interferometric Synthetic Aperture Radar and Global Positioning System data, Bull. seism. Soc. Am., 94(6b), 175-189.

Woessner, J., Jónsson, S., Sudhaus, H. \& Baumann, C., 2012, Reliability of Coulomb stress changes inferred from correlated uncertainties of finite-fault source models, J. geophys. Res., 117(B7).

Xu, W., Dutta, R. \& Jónsson, S., 2015, Identifying active faults by improving earthquake locations with InSAR data and Bayesian estimation: The 2004 Tabuk (Saudi Arabia) earthquake sequence, Bull. seism. Soc. Am., 105(2a), 765-775.

Yabuki, T. \& Matsu'ura, M., 1992, Geodetic data inversion using a Bayesian information criterion for spatial distribution of fault slip, Geophys. J Int., 109(2), 363-375.

Yagi, Y. \& Fukahata, Y., 2008, Importance of covariance components in inversion analyses of densely sampled observed data: an application to waveform data inversion for seismic source processes, Geophys. J Int., 175(1), 215-221.

Yagi, Y. \& Fukahata, Y., 2011, Introduction of uncertainty of Green's function into waveform inversion for seismic source processes, Geophys. J Int., 186(2), 711-720.

Zebker, H.A. \& Villasenor, J., 1992, Decorrelation in interferometric radar echoes, IEEE T. Geosci. Remote, 30(5), 950-959. 
Table 1: Information about fault solutions for the $2005 M_{w} 6.6$ Fukuoka earthquake estimated by different agencies/authors. Dips and strikes are according to the parameterization in our study. Faults with dip less and more than $90^{\circ}$ are dipping towards NE and SW, respectively. * indicates finite-fault solutions where the seismic moment is computed by summing up the slip amplitudes in each patch. \# indicates the solutions where only the deviatoric component of the moment tensor is constrained and their scalar moment is computed from the dominant eigenvalues of the moment tensor. \#\# indicates the moment tensor solution where the scalar moment is computed from the L2 norm of the eigenvalues of the moment tensor.

\begin{tabular}{|c|c|c|c|c|c|c|}
\hline Solution & Data used & $\begin{array}{l}\text { Seismic moment }[\mathrm{Nm}] \\
\text { (Moment magnitude) }\end{array}$ & $\begin{array}{c}\text { Centroid location } \\
\qquad\left[{ }^{\circ} \mathbf{E},{ }^{\circ} \mathbf{N}, \mathbf{k m}\right]\end{array}$ & $\begin{array}{l}\text { Strike } \\
{\left[\mathbf{N}^{\circ} \mathbf{E}\right]}\end{array}$ & Dip [ $\left.{ }^{\circ}\right]$ & Rake $\left[{ }^{\circ}\right]$ \\
\hline GCMT & Teleseismic & $9.02 \times 10^{18}(6.602)^{\#}$ & $130.15,33.72,12$ & 122 & 88 & -14 \\
\hline NEIC & Teleseismic & $1.052 \times 10^{19}(6.639)^{\# \#}$ & $130.131,33.807,10$ & 125 & 117 & -16 \\
\hline NIED F-net & Local broadband & $7.8 \times 10^{18}(6.565)^{\#}$ & $130.17,33.74,11$ & 122 & 93 & -11 \\
\hline Ito et al. (2006) & $\begin{array}{l}\text { Strong motion, } \\
\text { local broadband }\end{array}$ & $8.4 \times 10^{18}(6.586)^{\#}$ & $130.18,33.74,10$ & 123 & 94 & -4.3 \\
\hline Nishimura et al. (2006) & InSAR, GPS & $8.7 \times 10^{18}(6.596)^{*}$ & $130.297,33.683,7.4$ & 118 & 101 & -18 \\
\hline Asano \& Iwata (2006) & Strong motion & $1.15 \times 10^{19}(6.677)^{*}$ & $130.1918,33.7363,8.14$ & 122 & 93 & \\
\hline Takenaka et al. (2006) & Strong motion & & & 124 & 87 & -11 \\
\hline Horikawa (2006) & Strong motion & $5.7 \times 10^{18}(6.474)^{*}$ & $130.2011,33.7210,12$ & 122 & 91 & 8 \\
\hline Kobayashi et al. (2006) & $\begin{array}{l}\text { Strong motion, } \\
1-\mathrm{Hz} \text { GPS }\end{array}$ & $1 \times 10^{19}(6.637)^{*}$ & $130.2486,33.7074,6$ & 123 & 92.3 & -1 \\
\hline Sekiguchi et al. (2006) & Strong motion & $1.16 \times 10^{19}(6.68)^{*}$ & $130.2482,33.6985,4$ & 126 & 93 & \\
\hline Ozawa et al. (2006) & InSAR, GPS & & $130.2016,33.7264,5$ & 122 & 90 & \\
\hline our solution & InSAR, GPS & $8_{-0.65}^{+0.6} \times 10^{18}\left(6.568_{-0.024}^{+0.021}\right)^{*}$ & $\begin{array}{c}130.175_{-0.0102}^{+0.007} \\
33.7312_{-0.0035}^{+0.0071} \\
8.354_{-0.84}^{+1.23}\end{array}$ & $121.4_{-1.95}^{+2}$ & $95_{-5.7}^{+2.8}$ & \\
\hline
\end{tabular}




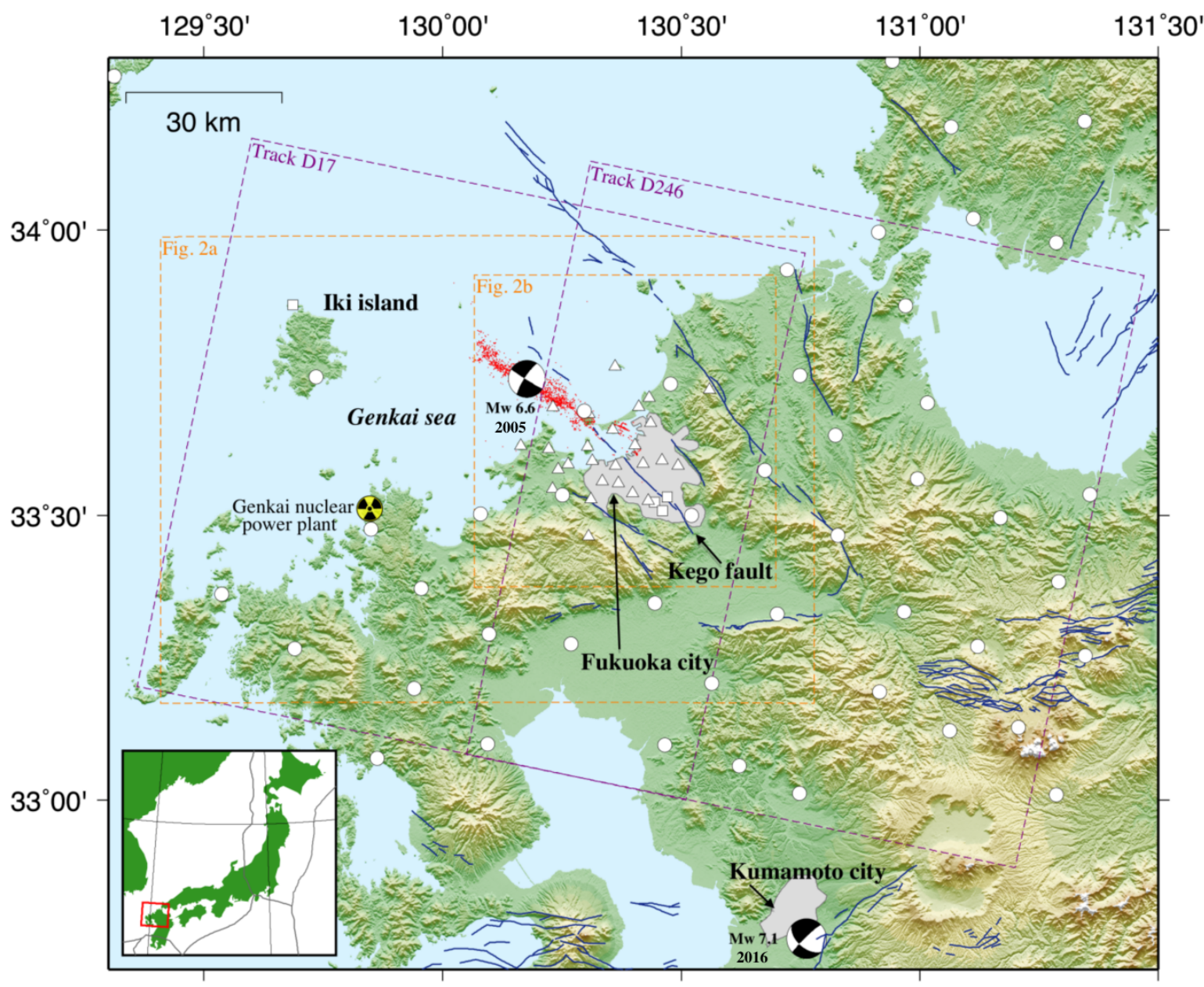

Figure 1. Shaded-relief topographic map of northwestern Kyushu (inset shows the location in Japan). Mapped active faults are shown in blue (Active fault database of Japan, AIST) and aftershocks as red dots (Uehira et al., 2006). Locations of GEONET continuous GPS stations (white circles), other continuous stations (white squares), as well as campaign GPS stations (white triangles) are also shown. Purple dashed rectangles mark areas covered by the descending radar scenes and orange rectangles the coverage of Fig. 2 . 


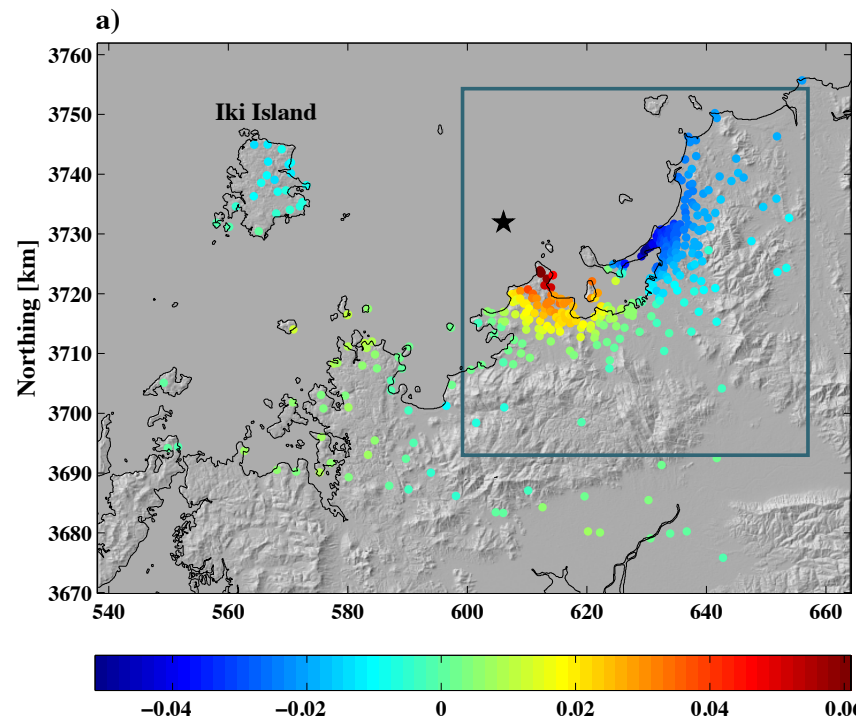

b)

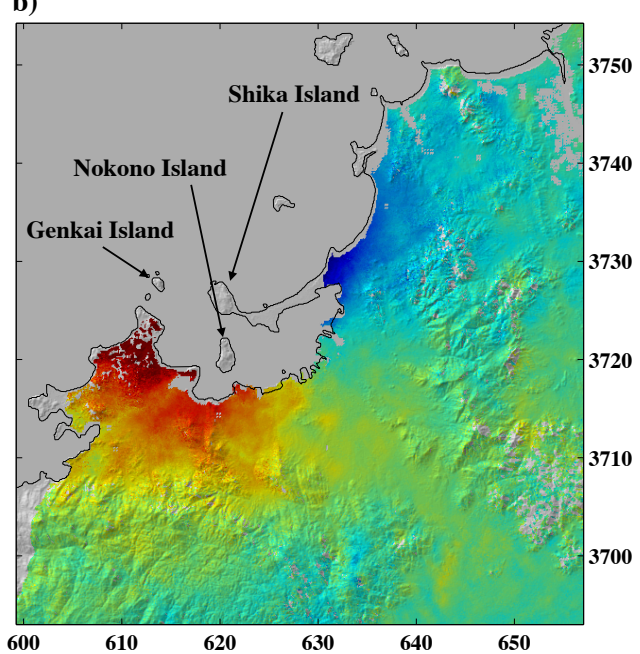

d)
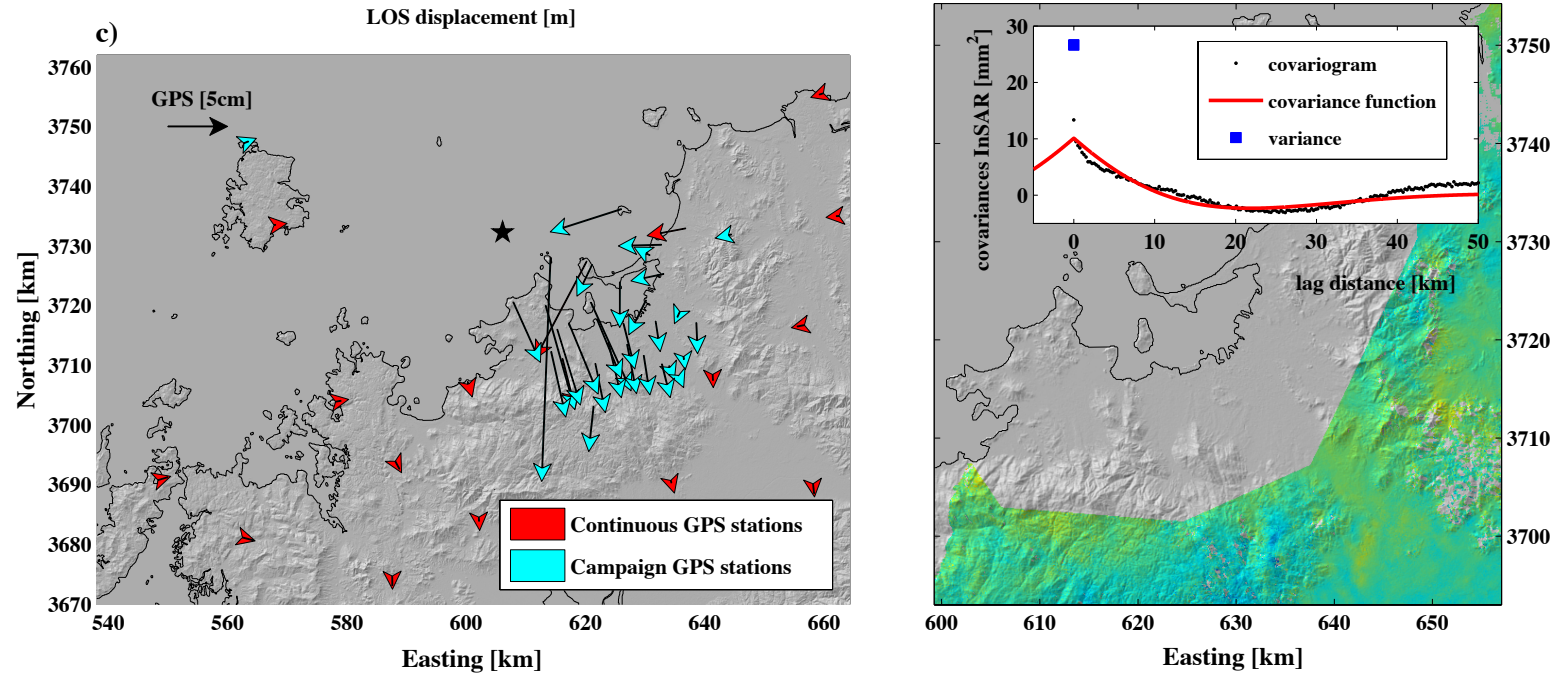

Figure 2. Observed coseismic displacements caused by the Fukuoka earthquake. a) Results of stable point target analysis of descending ENVISAT data from track 17 (in UTM coordinates, zone 52S). Blue rectangle shows the coverage of part (b) and (d). b) Descending ENVISAT interferogram from track 246. c) Horizontal GPS displacements obtained from continuous and campaign GPS stations. The black star in (a) and (c) indicates the epicenter of the earthquake. d) variance, sample covariogram and fitted covariance function (figure inset) of the noise of the undeformed region (shown) of data from track 246. 


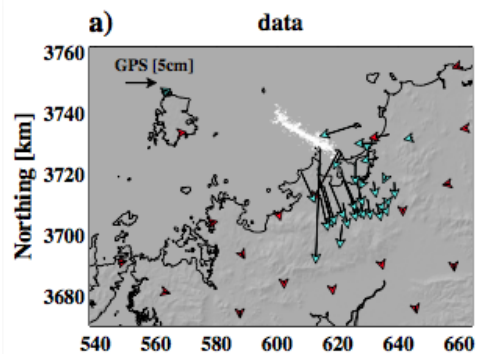

b) predicted data from MAP

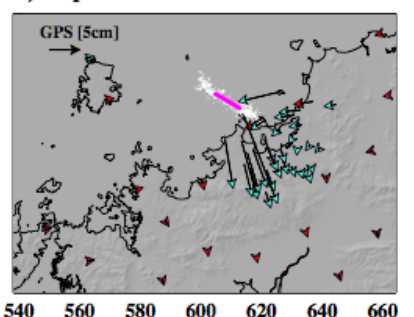

e)

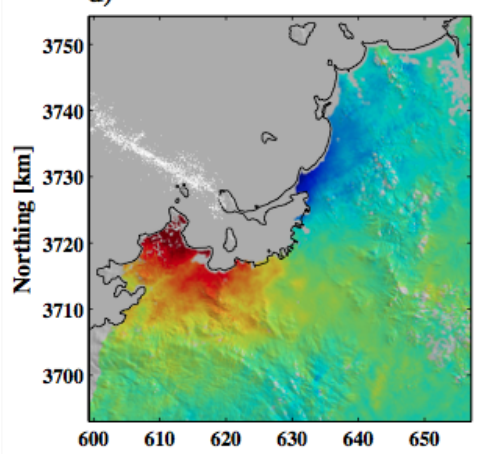

g)

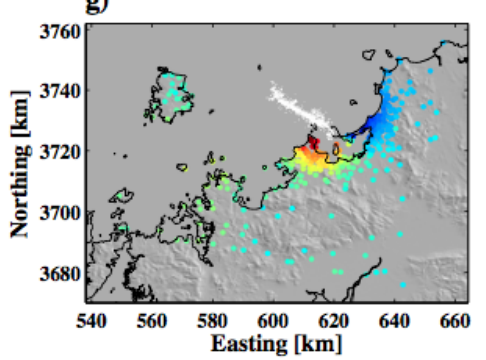

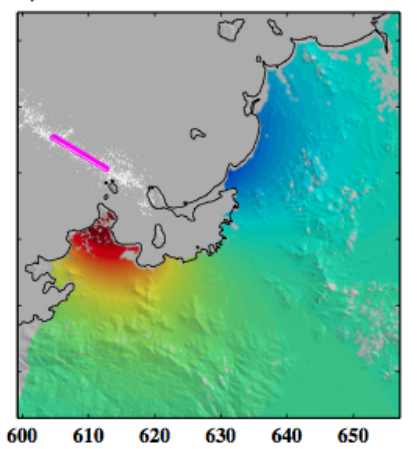

h)

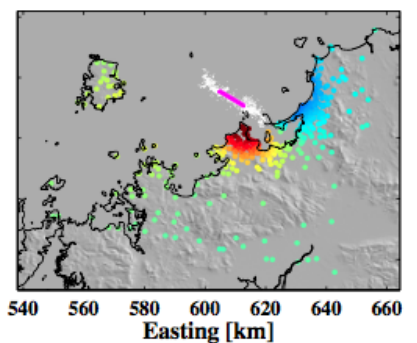

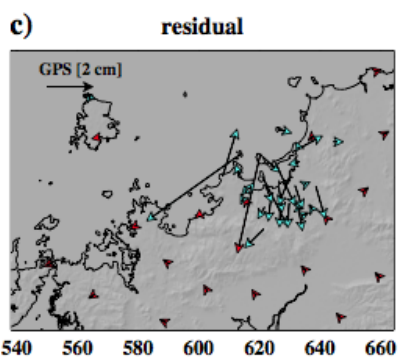

f)

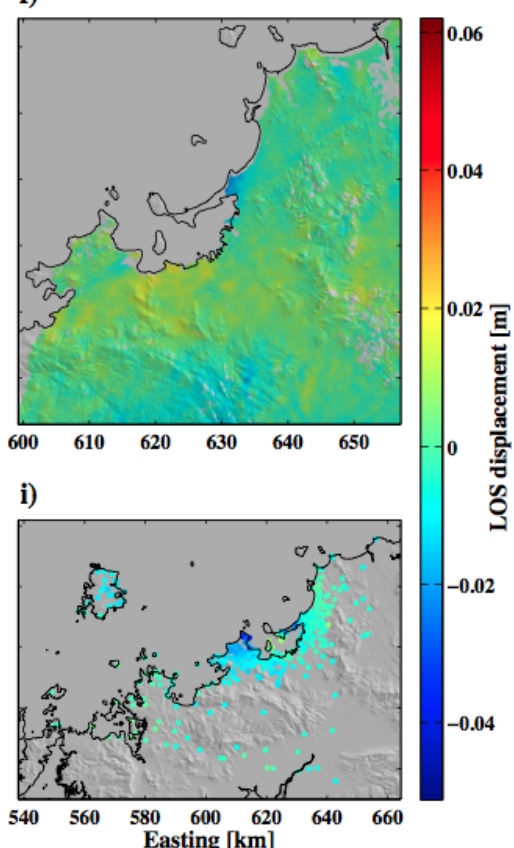

Figure 3. Model prediction and residuals using the maximum a posteriori fault parameters. a) data, b) model prediction, and c) residuals for the GPS horizontal data, $\mathrm{d}$ - $\mathrm{f}$ for the track 246 full-resolution data, and $\mathrm{g}$ - $\mathrm{i}$ for the track 17 subsampled point-target data. The aftershocks are shown as white dots. The surface projection of the best-fitting source fault (MAP), which is close to vertical, is shown in purple; the thick line marks the upper edge of the fault. 

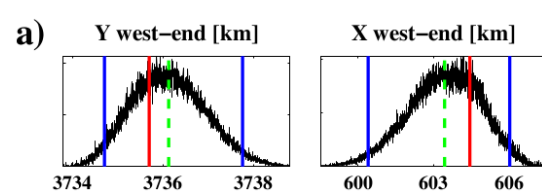

3738 Y west-end [km] 373 3734

$603 \quad 606$
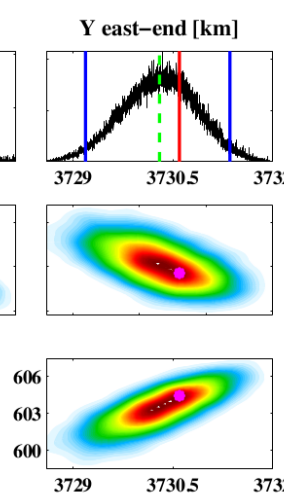

Y east-end [km] 3730.5

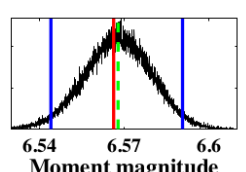

b) $95 \%$ confidence interval (mean-removed)

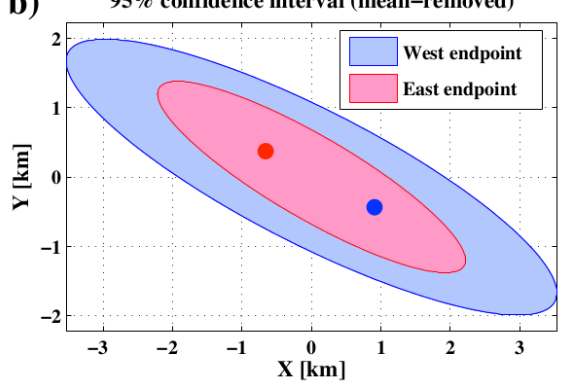

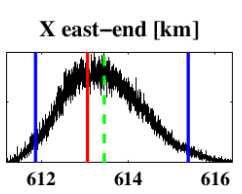
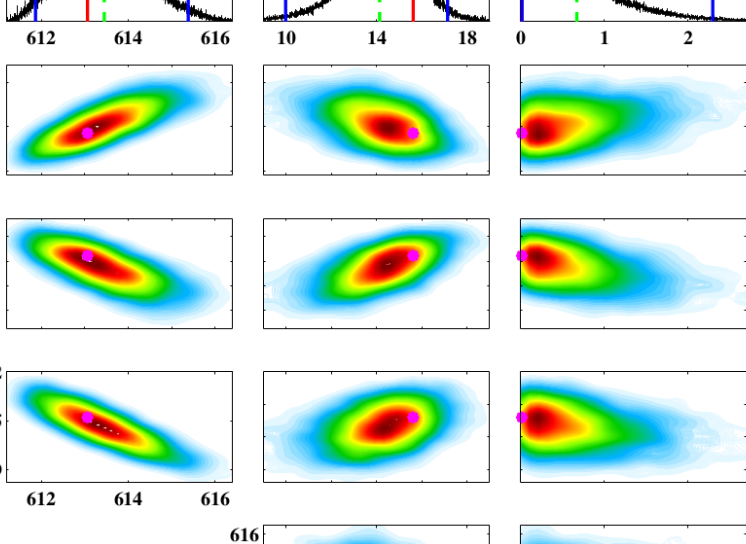

$\mathrm{X}$ east-end [km]

616
614
612
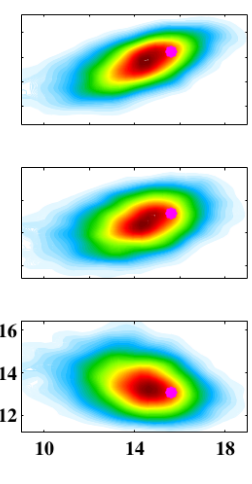

width $[\mathbf{k m}]$
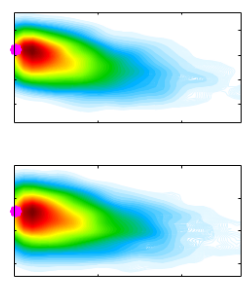

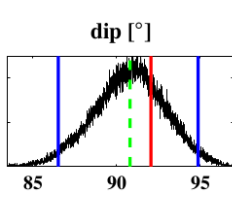

left-lateral
strike-slip $[\mathrm{m}]$
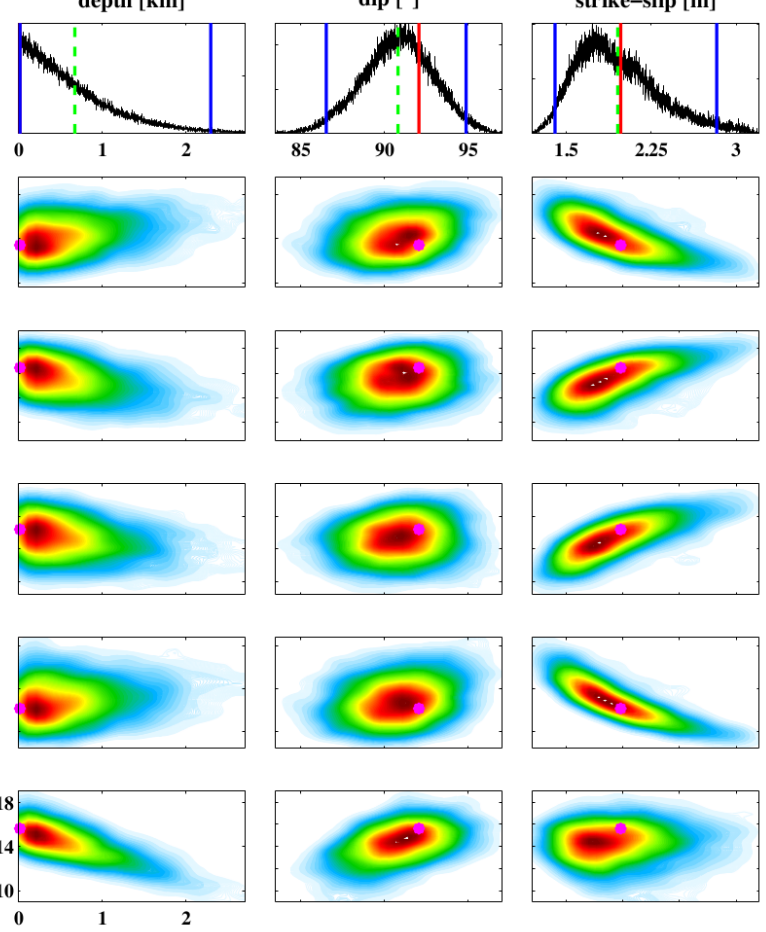

depth $[\mathrm{km}]$
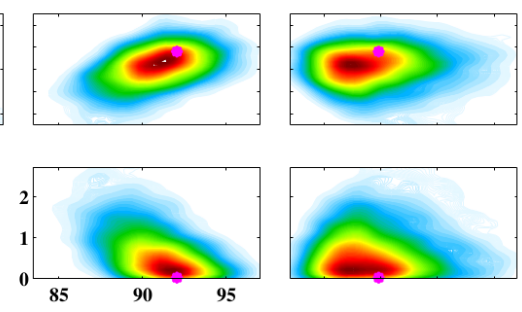

$\operatorname{dip}\left[^{\circ}\right]$

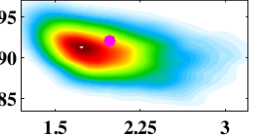

Figure 4. a) 1D and 2D marginal PDF plots of the fault model parameters estimated using both moment magnitude and aftershock location priors. Blue lines in the 1D marginal PDF plots show the 95\% confidence interval, the red line shows the maximum a posteriori (MAP) value and the green dashed line shows the posterior mean value. Hot colors in 2D marginal PDF plots show high probability regions and cold colors show low probability regions. The Pink dot in $2 \mathrm{D}$ marginal PDF plots shows the MAP value. The MAP estimate (pink dots and red lines) is within $0.225-\sigma$ of the true MAP. b) 2D marginal PDF with means removed for easting and northing of western (blue ellipse) and eastern endpoints (red ellipse) of the fault. The maximum a posteriori (with means removed) solution of western (blue dot) and eastern endpoints (red dot) are overlaid. 


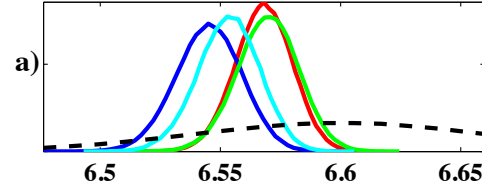

Moment magnitude

b)

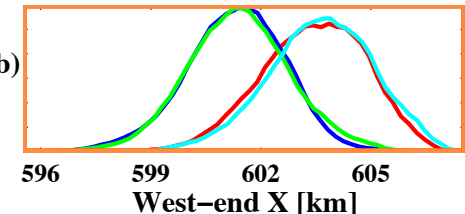

e)
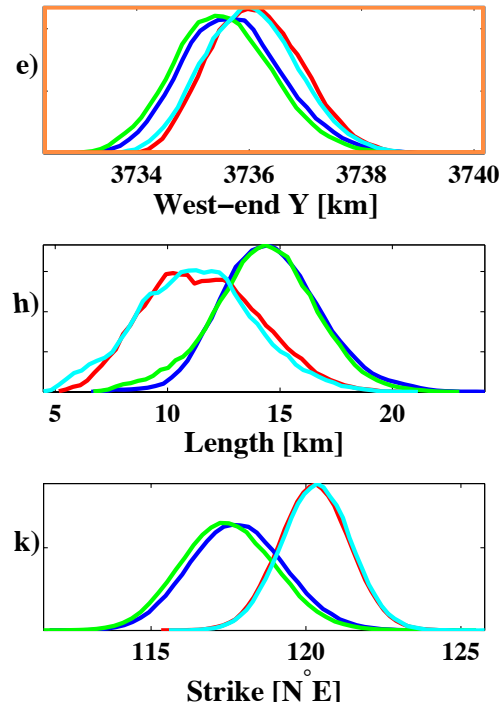

c)

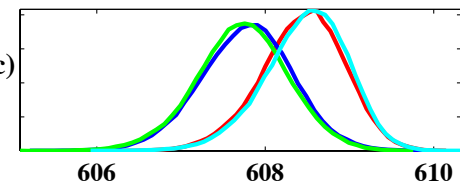

Center X [km]
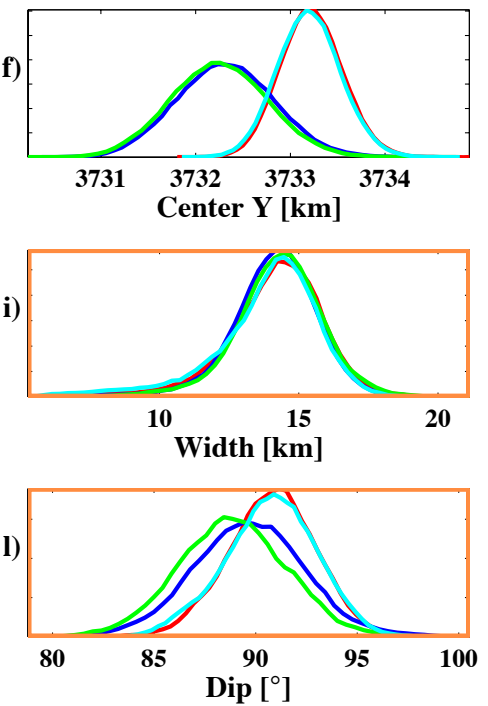

d)

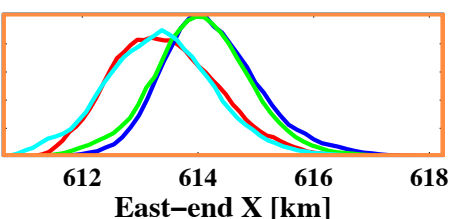

East-end X [km]
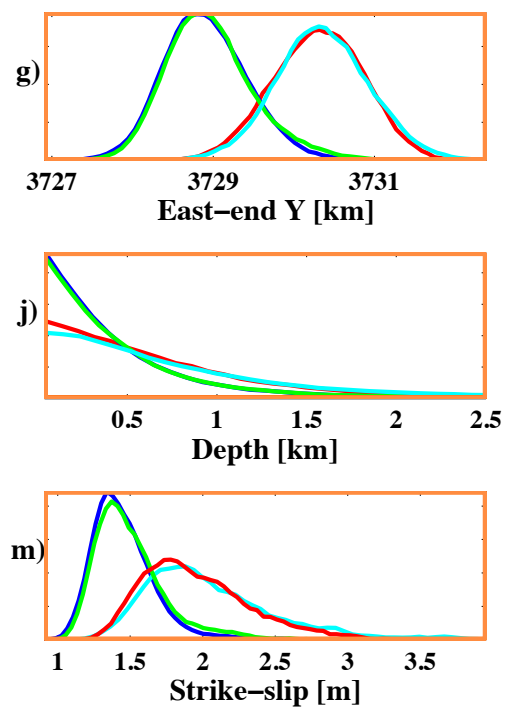

Figure 5. Comparisons of 1D marginals of the model parameters estimated using no priors (blue), only the aftershock locations prior (cyan), only the magnitude prior (green), and both priors (red). The black dashed line in (a) shows the moment magnitude prior distribution used. The fault model parameters that were sampled for using Bayesian inference are shown in orange boxes and the parameters derived from them are shown in black boxes. 


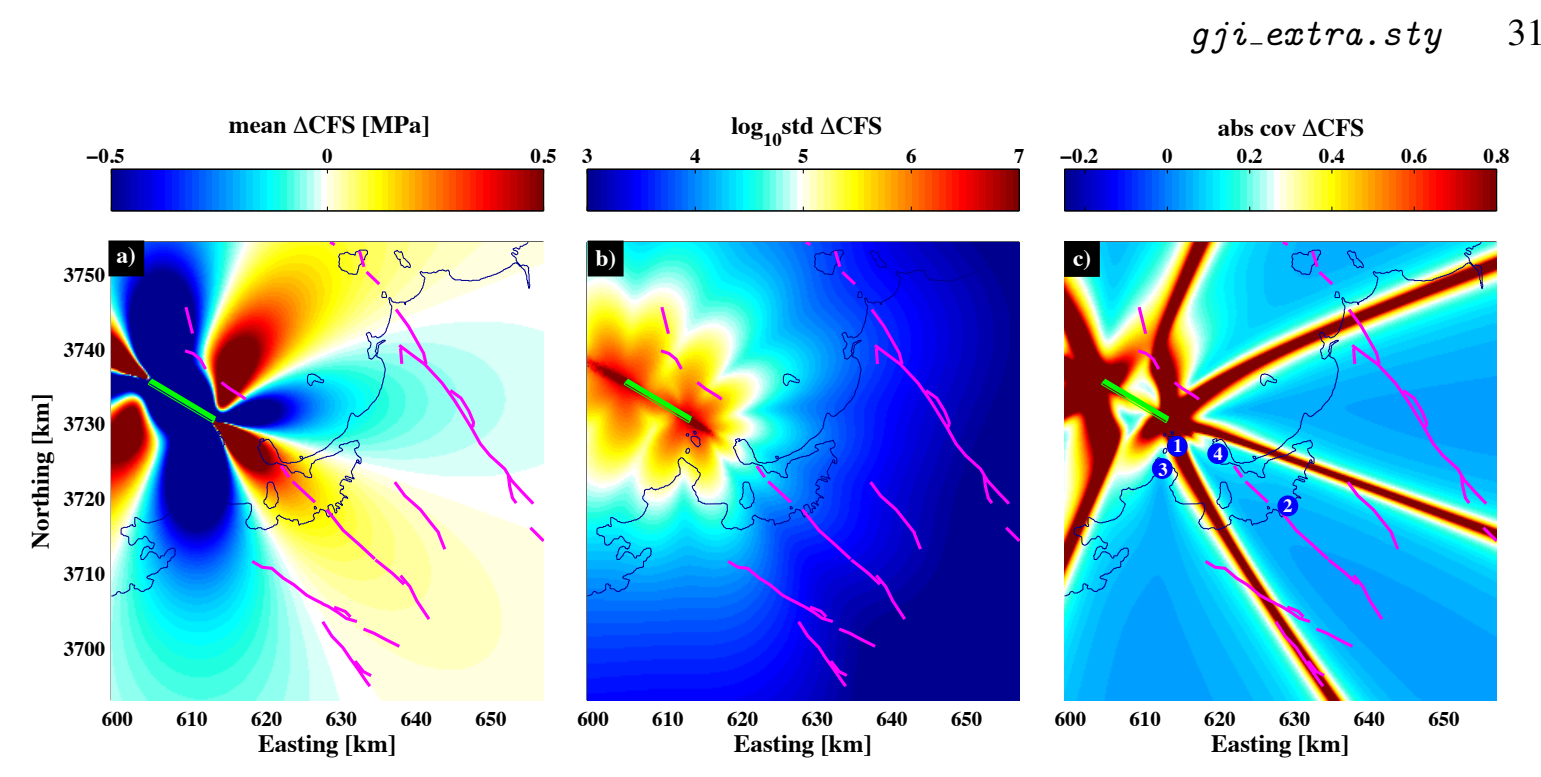

Figure 6. Calculated Coulomb Failure Stress changes ( $\triangle \mathrm{CFS}$ ) with, a) the mean of the $\Delta$ CFS maps, b) logarithm (base 10) of the standard deviation of the $\triangle$ CFS maps, and c) the coefficient of variation (ratio of standard deviation to mean) of the $\Delta$ CFS maps, showing high variations between $\Delta$ CFS lobes. Blue circles show the locations studied further in Fig. 7. Mapped active faults in the region are shown as magenta lines. 
32 Dutta, R., Jónsson, S., Wang, T. \& Vasyura-Bathke, $H$.
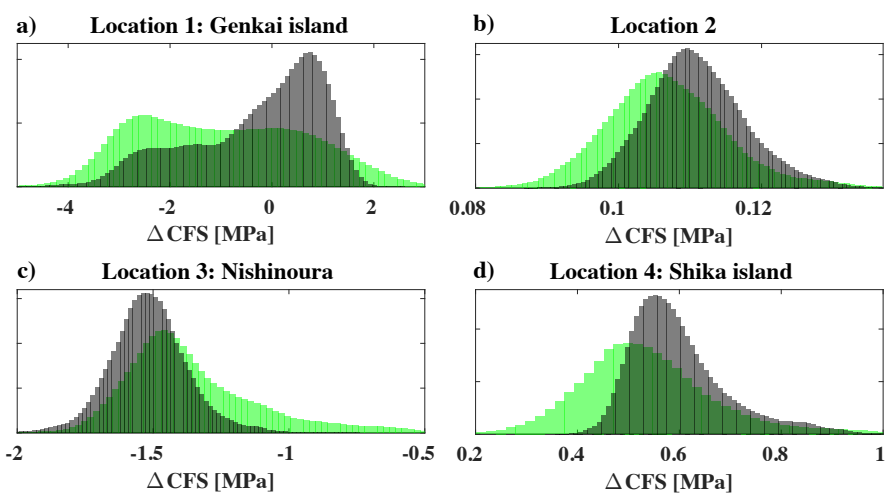

no priors

with both magnitude and aftershock locations priors

Figure 7. Estimated PDFs of the $\triangle \mathrm{CFS}$ using priors and without using priors at four locations shown in Fig. 6(c): a) Genkai island; b) on the Kego fault in Fukuoka city; c) Nishinoura; and d) Shika island. 

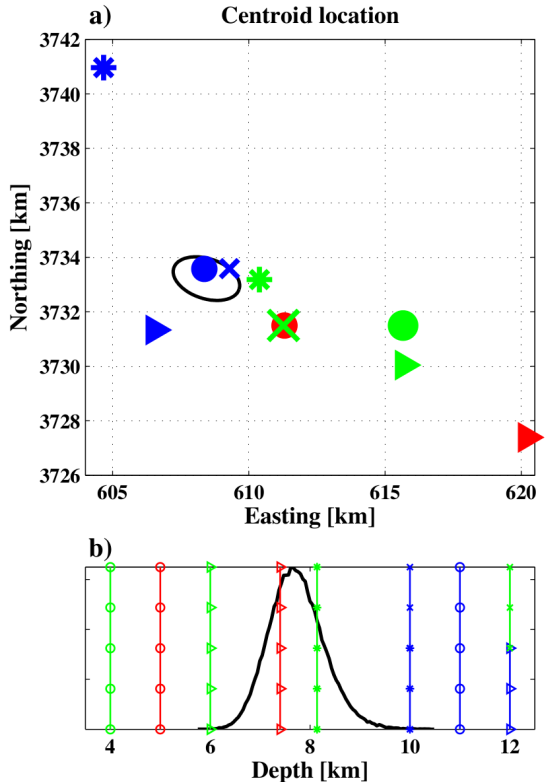

c)
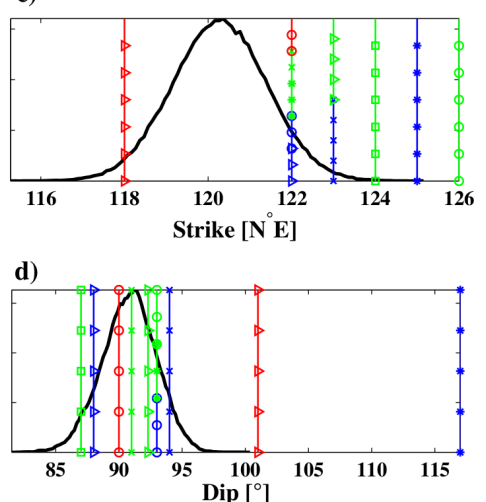

e)

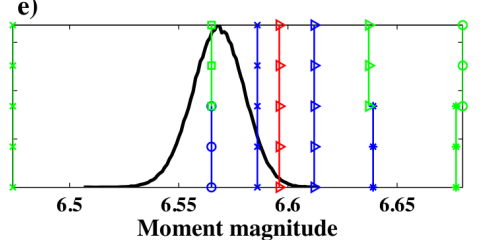

Geodetic data

— our solution Nishimura et al. (2006)

$\rightarrow$ Ozawa et al. (2006)

Teleseismic data

$\rightarrow$ GCMT

* * NEIC

$\because$ NIED F-net

$X \rightarrow$ Ito et al. (2006)

Strong motion data

* - Asano and Iwata (2006)

$\square-$ Takenaka et al. (2006)

$X-$ Horikawa et al. (2006)

$\rightarrow \rightarrow$ Kobayashi et al. (2006)

$\multimap$ Sekiguchi et al. (2006)

Figure 8. The estimated 1D/2D marginal PDFs of several key fault model parameters for the Fukuoka earthquake compared with deterministic solutions reported by several researchers and agencies. 
a)
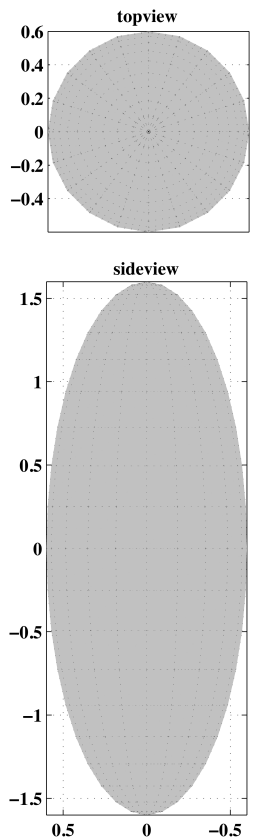

b)

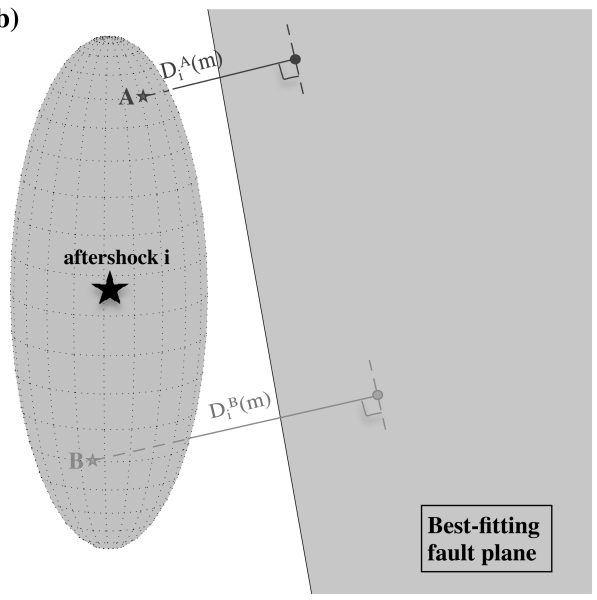

Figure A1. a) Topview and sideview of the ellipsoid of uncertainty around each aftershock location depicted as star. b) Perpendicular distances between the best-fitting fault plane and two sample locations, A and B, within the ellipsoid of uncertainty around $i^{t h}$ aftershock.

\section{APPENDIX A: AFTERSHOCK LOCATIONS PRIOR PARAMETERS}

In this appendix, we show how different parameters in the aftershock locations prior distribution (in Eq. 6) are defined. Consider there are $L$ number of aftershock locations. Using each aftershock location, we define $D_{i}\left(\mathbf{m}_{j}\right)$ as the perpendicular distance of that $i^{\text {th }}$ aftershock from the $j^{\text {th }}$ realization of fault model, $\mathbf{m}_{j}$. This is used to form a $L$-dimensional vector $D\left(\mathbf{m}_{j}\right)$ such that $D\left(\mathbf{m}_{j}\right)=$ $\left[D_{1}\left(\mathbf{m}_{j}\right) D_{2}\left(\mathbf{m}_{j}\right) \ldots D_{L}\left(\mathbf{m}_{j}\right)\right]^{T}$. For an ensemble of fault models, $\mathbf{m}$, the distribution of $D(\mathbf{m})$ will be positive valued.

The term, $\Sigma_{l}$, which is a $L \times L$ diagonal matrix, represents the error in $D(\mathbf{m})$ due to errors in the aftershock locations. The error in the aftershocks location is taken as $0.6 \mathrm{~km}$ in E-W and N-S directions and $1.6 \mathrm{~km}$ in depth (Uehira et al. 2006) that results in an ellipsoid of uncertainties around each aftershock location (Fig. A1a). To estimate $\Sigma_{l}$ (in Eq. 6), we first estimate the best fitting fault plane to the aftershock locations. For $i^{\text {th }}$ aftershock, we uniformly generate 100000 sample locations from within the ellipsoid of uncertainty and then calculate $D_{i}(\mathbf{m})$ for these sample locations with the best-fitting fault plane (shown in Fig. A1b). The variance of the resulting $D_{i}(\mathbf{m})$ samples is used as the $i^{\text {th }}$ diagonal entry of the $\Sigma_{l}$ error matrix. $\Sigma_{l}$ is used in the estimation of the hyperparameter $h_{2}^{2}$ (Appendix B) and to describe the aftershock locations prior PDF (in Eq. 6). 


\section{APPENDIX B: HYPERPARAMETER RELATED TO AFTERSHOCK LOCATIONS PRIOR}

Here we show how the hyperparameter $h_{2}{ }^{2}$ (in Eq. 6), which controls the relative weight between the aftershock locations prior and the likelihood function, is estimated from the uncertainties of the prior information. We estimate the variance of $D(\mathbf{m})^{T} \Sigma_{l}^{-1} D(\mathbf{m})$ (in Eq. 6) from the realizations of faultplane that fit the aftershock locations. These realizations of the fault-plane are obtained by estimating the uncertainties in the plane-fit to the aftershock locations, which is independent and a priori to the estimation of the fault-plane solution described in the paper. Considering the equation of a plane to be $P x+Q y+R z+1=0$, where $x, y$ and $z$ represent the location of the aftershocks in a 3D coordinate system. We consider $\delta_{i}(P, Q, R)$ as the perpendicular distance of $i^{\text {th }}$ aftershock from the plane with parameters $\mathrm{P}, \mathrm{Q}$ and $\mathrm{R}$, which is given as:

$$
\delta_{i}(P, Q, R)=\frac{\left|P x_{i}+Q y_{i}+R z_{i}+1\right|}{\sqrt{P^{2}+Q^{2}+R^{2}}}
$$

We consider a stochastic model such that $\boldsymbol{\delta}(P, Q, R)=\boldsymbol{\epsilon}_{4}$, where $\boldsymbol{\epsilon}_{4}$ follows a Gaussian distribution with zero mean vector and variance $\Sigma_{l}$ that represents the error in the aftershock locations. The posterior PDF of the fault plane parameters given the locations of the aftershock can be represented as:

$$
\begin{gathered}
\sigma_{M}(P, Q, R) \propto \exp \left[-\frac{1}{2} S(P, Q, R)\right] . \\
S(P, Q, R)=\sum_{i=1}^{L} w_{i} \cdot \delta_{i}{ }^{2}(P, Q, R)=\sum_{i=1}^{L} w_{i} \frac{\left(P x_{i}+Q y_{i}+R z_{i}+1\right)^{2}}{P^{2}+Q^{2}+R^{2}},
\end{gathered}
$$

$$
\text { where } w_{i}=\Sigma_{l i}^{-1}
$$

This posterior probability distribution is sampled using the Metropolis algorithm (Fig. A2). Considering $\tilde{\mathbf{m}}_{j}=\left[\begin{array}{lll}P_{j} & Q_{j} & R_{j}\end{array}\right]^{T}$, we can define $D\left(\tilde{\mathbf{m}}_{j}\right)$ (similar to $D(\mathbf{m})$ in Eq. 6) from the ensemble of plane-fits to the aftershock distribution, such that $D\left(\tilde{\mathbf{m}}_{j}\right)=\left[\begin{array}{llll}D_{1}\left(\tilde{\mathbf{m}}_{j}\right) & D_{2}\left(\tilde{\mathbf{m}}_{j}\right) & \cdots & D_{L}\left(\tilde{\mathbf{m}}_{j}\right)\end{array}\right]^{T}$, where each term of $D\left(\tilde{\mathbf{m}}_{j}\right)$ is the perpendicular distance between that $j^{\text {th }}$ plane-fit and L numbers of aftershocks and is given as: $D_{i}\left(\tilde{\mathbf{m}}_{j}\right)=\delta_{i}\left(P_{j}, Q_{j}, R_{j}\right)$. The units of $D(\tilde{\mathbf{m}})$ and $\Sigma_{l}$ are $m$ and $m^{2}$, respectively. An ensemble of $D(\tilde{\mathbf{m}})^{T} \Sigma_{l}^{-1} D(\tilde{\mathbf{m}})$ is thus calculated from all the obtained samples of plane parameters that fit the aftershock locations (Fig. A2d). The variance of the ensemble of $D(\tilde{\mathbf{m}})^{T} \Sigma_{l}^{-1} D(\tilde{\mathbf{m}})$ (shown in Fig. A2d), which is equal to 355, is taken as the value of the hyperparameter, $h_{2}^{2}$ (in Eq. 6). 
a)

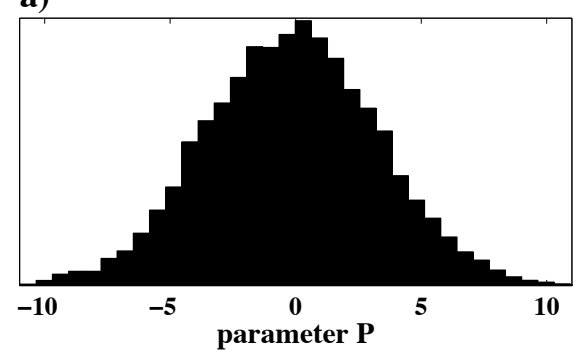

c)

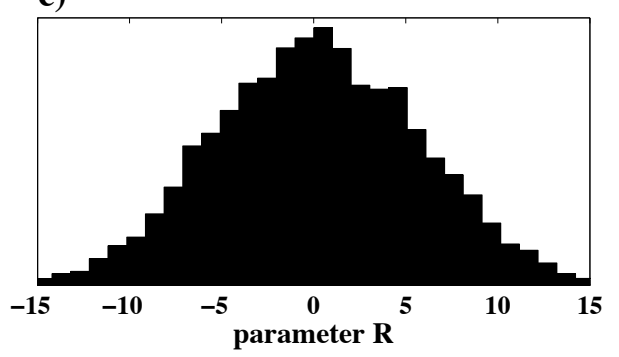

b)

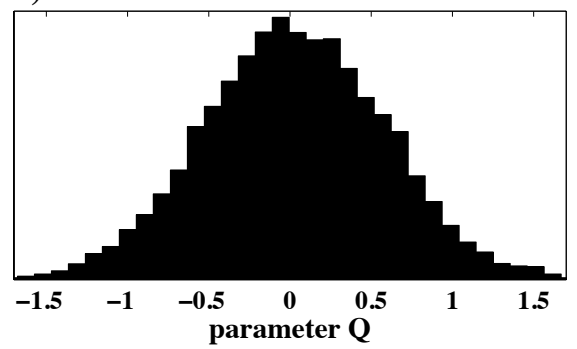

d)

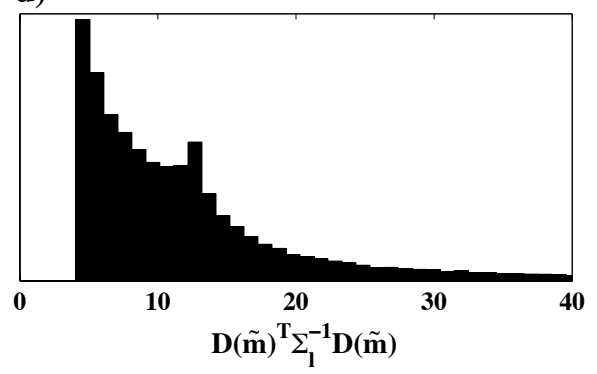

Figure A2. a-c) 1-D marginal posterior PDFs of fault plane model parameters, P, Q and R (in Eq. B.3). d) Probability distribution of $D(\tilde{\mathbf{m}})^{T} \Sigma_{l}^{-1} D(\tilde{\mathbf{m}})$ estimated from ensemble of fault plane parameters. 